\title{
Kindlin-2 regulates the differentiation of 3T3-L1 preadipocytes: implications for wound healing
}

\author{
Yuyan Pan ${ }^{1 \#}$, Qiang Wang ${ }^{1 \#}$, Wenjie Luan ${ }^{1}$, Yuedong Shi ${ }^{1}$, Jiaqi Liu ${ }^{1,2}$, Fazhi Qi ${ }^{1}$ \\ ${ }^{1}$ Department of Plastic Surgery, Zhongshan Hospital, Fudan University, Shanghai, China; ${ }^{2}$ Artificial Intelligence Center for Plastic Surgery and \\ Cutaneous Soft Tissue Cancers, Zhongshan Hospital, Fudan University, Shanghai, China \\ Contributions: (I) Conception and design: Y Pan; (II) Administrative support: F Qi, J Liu; (III) Provision of study materials or patients: J Liu; (IV) \\ Collection and assembly of data: Y Pan, Q Wang, W Luan; (V) Data analysis and interpretation: Y Pan, Q Wang, Y Shi; (VI) Manuscript writing: All \\ authors; (VII) Final approval of manuscript: All authors. \\ "These authors contributed equally to this work. \\ Correspondence to: Fazhi Qi, PhD; Jiaqi Liu, PhD. Department of Plastic and Reconstructive Surgery, Zhongshan Hospital, Fudan University, 180 \\ Fenglin Rd., Shanghai 200032, China. Email: qi.fazhi@zs-hospital.sh.cn; liujiaqi1213@yahoo.com.
}

Background: Adipose tissue has been proven to play a crucial role in wound healing, while kindlin-2, an integrin-associated protein, has been shown to regulate cell adhesion, migration, and differentiation. This study aimed to explore its involvement in the cell differentiation of 3T3-L1 preadipocytes and its role in wound healing.

Methods: Cell adhesion, Cell Counting Kit-8 (CCK-8), Transwell, and in vitro wound healing assays, along with adipogenic and osteogenic differentiation induction were performed in 3T3-L1 preadipocytes in which kindlin-2 was knocked down or overexpressed. In vivo, kindlin-2 (+/-) transgenic mice were constructed, and wound healing was analyzed by immunohistochemistry (IHC) in a mouse dorsal wound model. Realtime polymerase chain reaction (RT-PCR) and western blotting were performed to analyze the expression of adipokines and adipogenic markers in mouse wound tissues. Adipogenic differentiation induction of adipose tissue stromal vascular fraction (SVF) were performed, and the expression of adipogenic markers in SVF was detected by western blotting. The target signaling pathway highly related to adipogenic differentiation was explored by computational biology and verified by western blotting.

Results: Knockdown of kindlin-2 was found to inhibit the adhesion, migration, and adipogenic differentiation of 3T3-L1 preadipocytes while promoting their osteogenic differentiation. In contrast, kindlin-2 overexpression resulted in increased adhesion, migration, and adipogenic differentiation of 3T3L1 preadipocytes while reducing osteogenic differentiation. In vivo, downregulation of kindlin-2 inhibited adipogenesis in kindlin-2 transgenic mice, resulting in delayed wound healing by inhibiting inflammation, angiogenesis, collagen remodeling, and wound contraction. Mechanistically, we found that kindlin-2 could regulate adipogenic differentiation through PI3K/AKT/mTOR signaling pathway.

Conclusions: Our study revealed the essential role that kindlin-2 has in the differentiation and wound healing of 3T3-L1 preadipocytes, which offers a theoretical basis for further research and a novel strategy for wound healing.

Keywords: Kindlin-2; wound healing; 3T3-L1 preadipocyte; adipogenic differentiation; PI3K/AKT/mTOR signaling pathway

Submitted Nov 19, 2020. Accepted for publication Jan 08, 2021.

doi: $10.21037 /$ atm-21-176

View this article at: http://dx.doi.org/10.21037/atm-21-176 


\section{Introduction}

Wound healing is a coordinated repair process, which requires cooperation between multiple cell types to repair damaged tissue (1). Any abnormality that occurs will lead to poor wound healing, including scar hyperplasia and chronic ulcers, which affects about 6.5 million patients and incurs costs of over \$25 billion USD per year (2). In recent years, the role of adipose tissue in wound healing has received increasing attention and become a focal point in research in the field. Adipose tissue affects wound healing by regulating nutrient metabolism and participating in various biological processes, including immune response, inflammation, angiogenesis, adipogenesis, and bone morphogenesis by cytokines (3). Adipocytes can also migrate to wounds to clear the wound of cell debris and release antimicrobial peptides to fight wound infection (4-6). In addition, the dermal adipocytes generate myofibroblasts to repair skin damage after lipolysis and release fatty acids into skin wounds (7).

One-third of adipose tissue is composed of mature adipocytes, while the rest is a composed of other cells, including mesenchymal stem cells (MSCs), endothelial progenitor cells (EPCs), pericytes, and preadipocytes (8-10). During the process of adipogenesis, MSCs first differentiate into preadipocytes, and eventually differentiate into mature adipocytes (11). The differentiation of preadipocytes into adipocytes is a complex process regulated by a variety of transcription factors, including peroxisome proliferatorsactivated receptors (PPARs), CCAAT enhancer binding protein family (CCAAT enhancer binding proteins, C/ EBPs), fatty acid binding protein 4 (FABP4), and other key transcriptional regulators (12). Therefore, it is crucial to find a target that promotes the differentiation of preadipocytes into adipocytes, thereby promoting wound healing.

We noticed that kindlin (or fermitin), a family of focal adhesion proteins containing FERM domains, promotes integrin cell signaling and plays a key role in various cell activities (13). Kindlin-2 is an integrin-associated protein, encoded by the KINDLIN-2 gene, which has been shown to affect cell adhesion and migration and regulate cell differentiation (14). Kindlin-2 is strongly upregulated in human dermal fibroblasts (NHFs) and regulates adhesion and directed migration of NHFs by mediating the formation of focal adhesions (FAs) and stress fibers, which emphasizes its important role in wound healing and tissue remodeling (15). Our previous study found that
KINDLIN-2 gene knockdown through injections of adenoassociated virus with small interfering (si) RNA targeting the KINDLIN-2 gene could inhibit wound healing and increases neovascular permeability during angiogenesis in mice. This suggests that kindlin-2 may have an important function in wound healing, but the specific mechanism is still unclear (16). In terms of regulating cell differentiation, kindlin-2 is essential for chondrogenesis and regulates the differentiation of pluripotent cell-derived mesenchymal stromal cells (iPSC-MSCs) and bone marrow mesenchymal stem cells (BM-MSCs) (17-19). However, whether or not kindlin-2 regulates preadipocyte differentiation, its potential role in wound healing, and the underlying mechanism remain undetermined.

In this study, we investigated the function and mechanism of kindlin-2 regulation on the differentiation of 3T3-L1 preadipocytes. We utilized kindlin-2 (+/-) hybrid mice and a mouse model of wound healing to further explore the effect of kindlin-2 on adipogenic differentiation in wound healing. Our study confirmed that kindlin-2 plays a critical role in the differentiation and wound healing of 3T3-L1 preadipocytes. These findings may provide a theoretical basis for further research and have clinical applications in wound healing.

We present the following article in accordance with the ARRIVE reporting checklist (available at http://dx.doi. org/10.21037/atm-21-176).

\section{Methods}

\section{Cell culture, transfection, and differentiation}

3T3-L1 preadipocytes were purchased from a cell bank at the Chinese Academy of Sciences (Shanghai, China). Cells were cultured in Dulbecco's Modified Eagle Medium (DMEM, high-glucose, HyClone, USA) containing $10 \%$ fetal bovine serum (FBS, Invitrogen, USA). 3T3L1 preadipocytes were transfected with the pLKDCMV-G\&PR-U6-shRNA vector and the PGMLV-CMVKINDLIN2-HA-PGK-blasticidin vector which were purchased from OBiO Technology (Shanghai, China) and Genomeditech (Shanghai, China), respectively. The pLKDCMV-G\&PR-U6 vector and the PGMLV-CMV-HA-PGKblasticidin were used as negative controls. The transfection efficiency was examined by western blot and real-time polymerase chain reaction (RT-PCR). For induction of adipogenic differentiation, cells were cultured in adipogenic differentiation medium kit (Cyagen, Suzhou, China). After 
being cultured for 21 days according to the protocol, cells were fixed in $4 \%$ paraformaldehyde solution for 30 minutes and then stained with Oil Red O (Cyagen, Suzhou, China) for 30 minutes at room temperature. For induction of osteogenic differentiation, cells were cultured in osteogenic differentiation medium kit (Cyagen, Suzhou, China). After being cultured for 21 days according to the protocol, cells were fixed in $4 \%$ paraformaldehyde solution for 30 minutes and then stained with Alizarin Red (Cyagen, Suzhou, China) for 5 minutes at room temperature.

\section{Quantitative RT-PCR analysis}

Total RNA was extracted from both tissues and cultured cells using TRIzol reagent (Invitrogen, Carlsbad, CA USA) and reverse-transcribed into complement DNA (cDNA) with a PrimeScript RT Reagent Kit (Takara Bio Inc., Shiga, Japan) according to the protocol. SYBR Green Real-time PCR Master Mix (Yeasen, Shanghai, China) was used for RT-PCR analyses and carried out in an ABI 7500 RealTime PCR system (Applied Biosystems, Foster City, CA, USA). The relative gene expression level was determined using the $2^{-\Delta \Delta \mathrm{Ct}}$ method. The primer sequences for RT-PCR are shown in Table $\mathrm{S} 1$.

\section{Western blotting analysis}

For total protein extraction from tissues, tissues frozen from liquid nitrogen were homogenized and incubated on ice for $30 \mathrm{~min}$ in $500 \mu \mathrm{L}$ radioimmunoprecipitation assay (RIPA) and $5 \mu \mathrm{L}$ phenylmethylsulfonyl fluoride (PMSF). The lysate was centrifuged at $12,000 \mathrm{~g}$ for 15 minutes at $4{ }^{\circ} \mathrm{C}$. The protein concentration was determined by using a bicinchoninic acid (BCA) assay (Thermo Fisher Scientific, USA). For total protein extraction from cultured cells, and cell lysates were obtained using the RIPA buffer. Total protein $(15 \mu \mathrm{g})$ was injected into Bis-Tris SDS/PAGE gel and transferred onto polyvinylidene difluoride (PVDF) membranes. After blocking with $5 \%$ bovine serum albumin (BSA) for $60 \mathrm{~min}$, the membranes were incubated with primary antibodies overnight at $4{ }^{\circ} \mathrm{C}$. The membranes were then exposed to the secondary antibody for $60 \mathrm{~min}$. The bands were developed with an enhanced chemiluminescence (ECL) kit (Beyotime Biotechnology, Shanghai, China) and analyzed with an imaging system. Quantification of the densitometry was performed by using Image $\mathrm{J}$ software [National Institutes of Health (NIH), Bethesda, MD, USA]. All the antibodies are listed in Table S2.

\section{Adhesion, Cell Counting Kit-8 (CCK-8), Transwell, and wound closure assays}

For the adhesion assay, the cells were seeded into the 24well plate at a density of $10^{5}$ cells per well with a round cell slide previously inserted. The round cell slides were picked out at 2, 4, and $6 \mathrm{~h}$, placed in new wells, and fixed with $4 \%$ paraformaldehyde for 30 minutes. The cells were then stained with DAPI (Sigma-Aldrich, St. Louis, MO, USA) $(1: 5,000)$ for $5 \mathrm{~min}$. Fluoromount-G (Southern Biotech, Birmingham, AL, USA) was used to prevent fluorescence quenching. The numbers of adhesive cells were quantified under fluorescence microscope. For the CCK-8 assay, cells were inoculated into 96-well plates at a density of 2,000 cells per well. Then, $10 \mu \mathrm{L}$ of CCK-8 reagent (Yeasen, Shanghai, China) was added to the well at 24,48 , and $72 \mathrm{~h}$. The plates were incubated for $2 \mathrm{~h}$, and the absorbance was determined at $450 \mathrm{~nm}$. For the Transwell assay, 24-well Transwell plates ( $8 \mu \mathrm{m}$ pore size, Corning, Corning, NY, USA) were used. Cells $\left(1 \times 10^{4}\right)$ in serum-free medium $(200 \mu \mathrm{L})$ were seeded in the upper chamber, and $800 \mu \mathrm{L}$ of complete medium was then added to the lower chamber. After incubation for 24 and $48 \mathrm{~h}$, the membrane was washed briefly with phosphate-buffered saline (PBS), fixed with $4 \%$ paraformaldehyde, and stained with crystal violet for $5 \mathrm{~min}$ at room temperature. The number of stained cells was counted under a microscope. For the in vitro wound healing assay, scratch wounds were produced by a $200 \mu \mathrm{L}$ pipette tip. The average distance migrated by the cells was observed at $0,2,4$, and $6 \mathrm{~h}$ under a microscope and measured by Image J software (NIH).

\section{Immunofluorescence staining}

The cells were immersed in $0.1 \%$ Triton $\mathrm{X}-100$ PBS for $10 \mathrm{~min}$ at room temperature, and were then washed three times with PBS. The cells were incubated with primary antibodies at $4{ }^{\circ} \mathrm{C}$ overnight. The cells were then washed with PBS and incubated with Alexa Fluor 594/488-conjugated anti-rabbit secondary antibodies (1:300) (Jackson ImmunoReasearch, West Grove, PA, USA) for $1 \mathrm{~h}$ at room temperature. After being washed three times with PBS, the cells were then stained with DAPI $(1: 5,000)$ for $30 \mathrm{~min}$ at room temperature. Fluoromount-G was used to prevent fluorescence quenching. The numbers of immunofluorescence-positive cells were quantified from five microscopic fields and the percentages of positive cells were quantified by Image J software (NIH). 


\section{Immunobistochemistry}

The sections were deparaffinized, rehydrated, immersed in antigen-retrieval buffer, and treated with diluted hydrogen peroxide $(0.3 \%)$. Then, the sections were incubated with primary antibodies (listed in Table S2) at $4{ }^{\circ} \mathrm{C}$ overnight. Subsequently, the sections were stained with horseradish peroxidase (HRP)-labeled secondary antibodies (listed in Table S2) and diaminobenzidine (DAB, Gene Tech, Shanghai, China). Finally, the slides were counterstained with hematoxylin, dehydrated, cleared and, coverslipped. The images were quantified using Image J software (NIH).

\section{In vivo assay}

C57BL/6 mice (age, 8-9 weeks old; weight, $20-25 \mathrm{~g}$; half males and half females) were obtained from the Shanghai SLAC Laboratory Animal Co., Ltd. (China) and raised in a specific pathogen-free (SPF) animal laboratory at Zhongshan Hospital affiliated to Fudan University. Kindlin-2 transgenic mice were purchased from the Nanjing Biochemical Research Institute (China). The mice were divided into two groups: kindlin-2 (+/-) transgenic mice formed the experimental group $(\mathrm{n}=30)$, while wildtype (WT) C57BL/6 mice formed the control group $(n=30)$.

The mice were anesthetized by intraperitoneal injection of $50 \mathrm{mg} / \mathrm{kg} 1 \%$ pentobarbital. For the wound model, the dorsal skin was shaved and sterilized by $75 \%$ ethanol after anesthesia. A $6 \mathrm{~mm}$ skin drill was used to create a round wound, and then the full-thickness skin was removed. For 10 consecutive days postoperation (from day 1 to day 10), the wound healing of each group was recorded daily under the same scale with a digital camera. The percentage wound area (wound area/day 0 wound area $\times 100 \%$ ) was used to evaluate the wound healing process. The pictures were analyzed with Image J software (NIH).

The wound tissue, along with the normal skin and subcutaneous tissues around the wound, was extracted at $24 \mathrm{~h}$ (day 1), $72 \mathrm{~h}$ (day 3), $120 \mathrm{~h} \mathrm{(day} \mathrm{5),} \mathrm{and} 168 \mathrm{~h} \mathrm{(day} \mathrm{7)}$ after modeling. Some of the tissues were fixed with $4 \%$ paraformaldehyde for $24 \mathrm{~h}$, gradient alcohol-dehydrated, paraffin-embedded, and sectioned for hematoxylin and eosin (HE), and immunohistochemistry (IHC) staining. Other tissues were placed in liquid nitrogen for RNA extraction or western blotting. SVF was isolated from inguinal adipose tissue. The inguinal adipose tissue was digested with collagenase D (Roche, Shanghai, China). The compound was then filtered with $70 \mu \mathrm{L}$ cell strainers to obtain SVF cells. All experimental procedures were approved by the Animal Care Committee of Zhongshan Hospital affiliated to Fudan University (NO.: 2017-007). Experiments were performed in compliance with national guidelines for the care and use of animals.

\section{Computational biology analysis}

Pubmed2ensembl (http://pubmed2ensembl.ls.manchester. ac.uk) was used to perform text mining (20). In this study, the terms "adipogenic differentiation" and "adipogenesis" were queried to search for genes that are highly related to adipogenic differentiation or adipogenesis. "Ensembl Gene ID" and "Associated Gene Name" under "GENE" were selected and "Search for PubMed IDs" and "Filter on Entrez: PMID" drop-down menus were chosen in the search of every query. Then, the queries returned two lists of genes, the intersection of which was then used for the next steps.

The Search Tool for the Retrieval of Interacting Genes/Proteins (STRING) (http://string-db.org) was used to analyze the protein-protein interactions of the selected genes. The genes that were highly related to adipogenic differentiation retrieved in the previous step and KINDLIN-2 were further analyzed for protein-protein interactions, and the signaling pathways highly related to adipogenic differentiation were obtained.

\section{Statistical analysis}

All statistical analyses were carried out using the SPSS Statistics 21 (IBM Corp., Armonk, NY, USA) and GraphPad Prism 7 (San Diego, CA, USA). All in vitro experiments were repeated at least three times, and the values are presented as the mean \pm standard deviation (SD). Student's $t$-test was used for comparisons between two groups. A P value $<0.05$ was considered statistically significant.

\section{Results}

\section{Kindlin-2 regulated adbesion and proliferation of 3T3-L1 preadipocytes}

We first knocked down and overexpressed kindlin-2 in 3T3-L1 preadipocytes. RT-PCR demonstrated the successful transfection of 3T3-L1 preadipocytes $(\mathrm{P}<0.01)$ (Figure 1A). Correspondingly, the reduction and overexpression of the level of kindlin-2 were confirmed by 
western blotting $(\mathrm{P}<0.01)$ (Figure $1 B, C)$.

Cell adhesion assays showed that kindlin-2 regulated adhesion of 3T3-L1 preadipocytes. The number of adherent cells was decreased after kindlin-2 knockdown compared to the corresponding control group and increased in the kindlin-2-overexpressing cells compared to the corresponding control group at 2, 4, and $6 \mathrm{~h}$ after plating. This showed that downregulation of kindlin-2 inhibited adhesion, whereas upregulation of kindlin-2 promoted adhesion of 3T3-L1 preadipocytes $(\mathrm{P}<0.01)$ (Figure 1D,E).

Cell proliferation rate was detected by CCK-8 kit at 24, 48 , and $72 \mathrm{~h}$ after plating. The results showed no significant difference in the proliferation of each group, implying that kindlin-2 did not affect the proliferation of 3T3-L1 preadipocytes (Figure $1 F$ ).

\section{Kindlin-2 regulated the migration of 3T3-L1 preadipocytes}

Transwell assays showed that the number of transmigrated cells decreased after kindlin-2 knockdown, which was significantly lower than that of the control group both at 24 and $48 \mathrm{~h}$. The number of transmigrated cells increased in the kindlin-2-overexpressing cells, which was significantly higher than that in the control group both at 24 and $48 \mathrm{~h}(\mathrm{P}<0.01)$ (Figure $2 A, B, C)$. Next, in vitro wound healing assays demonstrated that cells in which kindlin-2 was knocked down closed scratch wounds slower than the control group, whereas the migration rate of kindlin2 -overexpressing cells was significantly higher than that of the control group both at 6,12 , and $18 \mathrm{~h}(\mathrm{P}<0.05)$ (Figure 2D,E).

\section{Kindlin-2 regulated adipogenic differentiation of 3T3-L1 preadipocytes}

After adipogenic differentiation induction, kindlin-2knocked down preadipocytes were hardly differentiated into adipocytes as revealed by the reduced Oil Red O staining area compared with the control group, whereas Kindlin2-overexpressing cells were almost fully differentiated into adipocytes as revealed by a much greater Oil Red $\mathrm{O}$ staining area compared with the corresponding control group $(\mathrm{P}<0.01)$ (Figure $3 A, B)$.

RT-PCR and western blotting were then performed to analyze messenger RNA (mRNA) and protein levels of adipogenic markers, including proliferator-activated receptor $\gamma(\mathrm{PPAR} \gamma)$, CCAAT/enhancer-binding protein
$\alpha(\mathrm{C} / \mathrm{EBP} \alpha)$ and fatty acid-binding protein 4 (FABP4), respectively. Consistent with the staining results, both mRNA and protein levels of PPAR $\gamma, \mathrm{C} / \mathrm{EBP} \alpha$, and FABP4 were dramatically decreased in kindlin-2-knockdown cells compared with those in control group and increased in kindlin-2-overexpressing cells compared with those in the corresponding control group $(\mathrm{P}<0.01)$ (Figure $3 C, D, E, F, G)$. Immunofluorescence staining showed that the expression of the adipogenic markers, PPAR $\gamma$ and FABP4 in the kindlin2-knockdown cells was significantly decreased compared with that in the control group, whereas the expression of PPAR $\gamma$ and FABP4 in the kindlin-2-overexpressing cells was significantly higher than that in the corresponding control group $(\mathrm{P}<0.01)$ (Figure $3 H, I, \mathcal{F}, K)$.

\section{Kindlin-2 regulated osteogenic differentiation of 3T3-L1 preadipocytes}

Contrary to the results of adipogenic differentiation, kindlin-2-knockdown cells were fully differentiated into osteocytes after osteogenic differentiation induction as revealed by more intense Alizarin Red staining compared with the control group, whereas kindlin-2-overexpressing cells were hardly differentiated into osteocytes as revealed by less intense Alizarin Red staining area compared with the corresponding control group $(\mathrm{P}<0.01)$ (Figure $4 A, B)$.

RT-PCR and Western blotting were then performed to analyze mRNA and protein levels of osteogenic markers, alkaline phosphatase (ALP), and Runt-related transcription factor 2 (Runx2). Consistent with the staining results, both mRNA and protein levels of ALP and Runx2 were dramatically increased in kindlin-2-knockdown cells compared with those in the control group and decreased in kindlin-overexpressing cells compared with those in the corresponding control group $(\mathrm{P}<0.05)$ (Figure $4 C, D, E, F)$.

\section{Downregulation of kindlin-2 inbibited adipogenesis in vivo}

We next investigated the function of kindlin-2 in the regulation of adipogenesis in vivo. We first constructed kindlin-2 (+/-) transgenic mice, the gene sequence of which inserted $\mathrm{a}+13$ or $+20 \mathrm{bp}$ fragment and compared them with the WT mice (Figure 5A). After modeling the full-thickness excisional skin wounds on the dorsum of the kindlin-2 (+/-) and WT mice, we observed that WT mice showed a significantly smaller wound size as compared with the kindlin-2 (+/-) mice during the wound healing process 


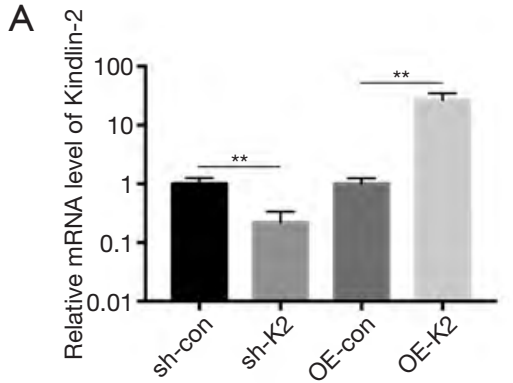

B

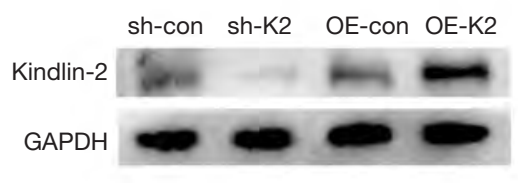

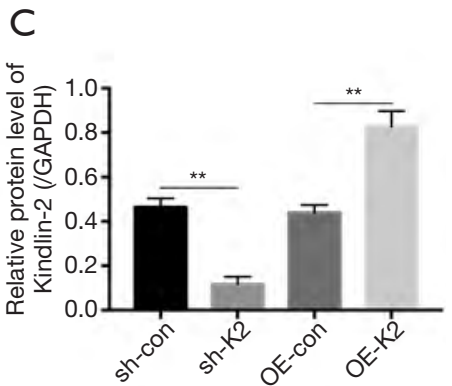

sh-K2
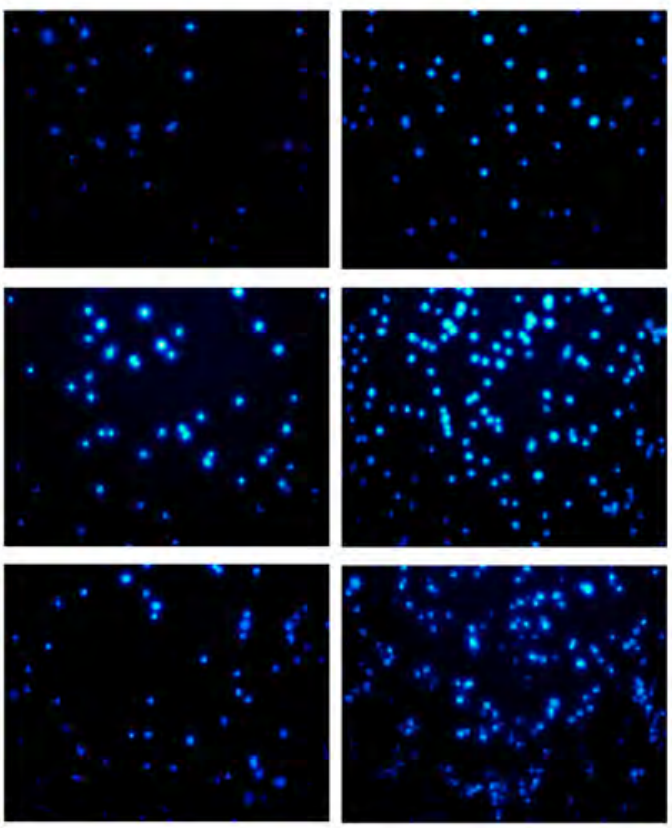

$\mathrm{F}$

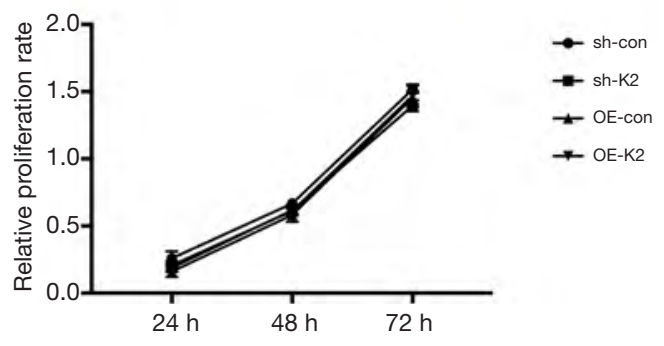

Figure 1 Kindlin-2 regulates adhesion and proliferation of 3T3-L1 preadipocytes. (A) RT-PCR analysis for the expression of kindlin-2 in 3T3-L1 preadipocytes with kindlin-2 overexpression or knockdown after transfection. (B) Western blotting analysis for kindlin-2 to analyze the transfection efficiency. (C) Quantification for protein levels of kindlin-2 relative to that of GAPDH. (D) Cell adhesion assay observed by immunofluorescence at 2, 4, and $6 \mathrm{~h}$ after plating. The cells were stained with DAPI. Magnification: 200x. (E) The number of adherent cells at 2, 4, and $6 \mathrm{~h}$ after plating. (F) Cell proliferation rate by CCK-8 kit at 24, 48, and $72 \mathrm{~h}$ after plating. ${ }^{* *}, \mathrm{P}<0.01$. RT-PCR, real-time polymerase chain reaction; GAPDH, glyceraldehyde phosphate dehydrogenase; CCK-8, cell counting kit-8. 
A

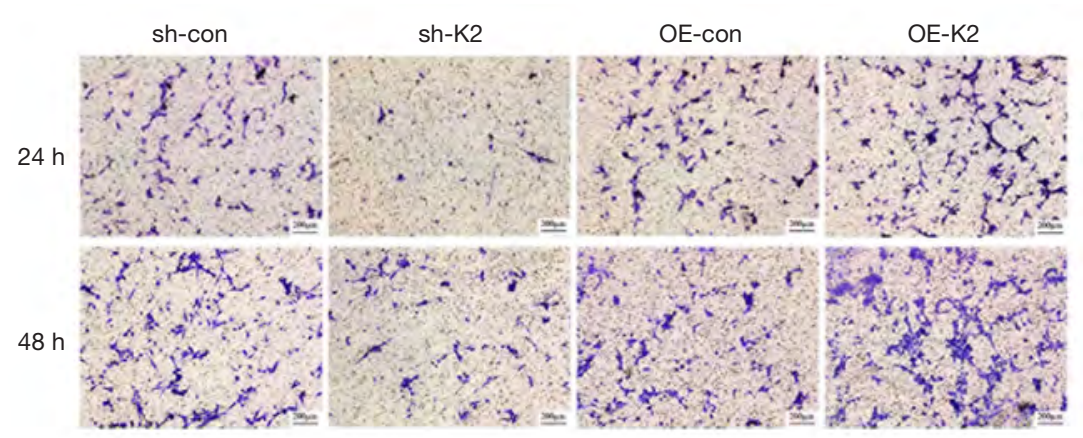

D
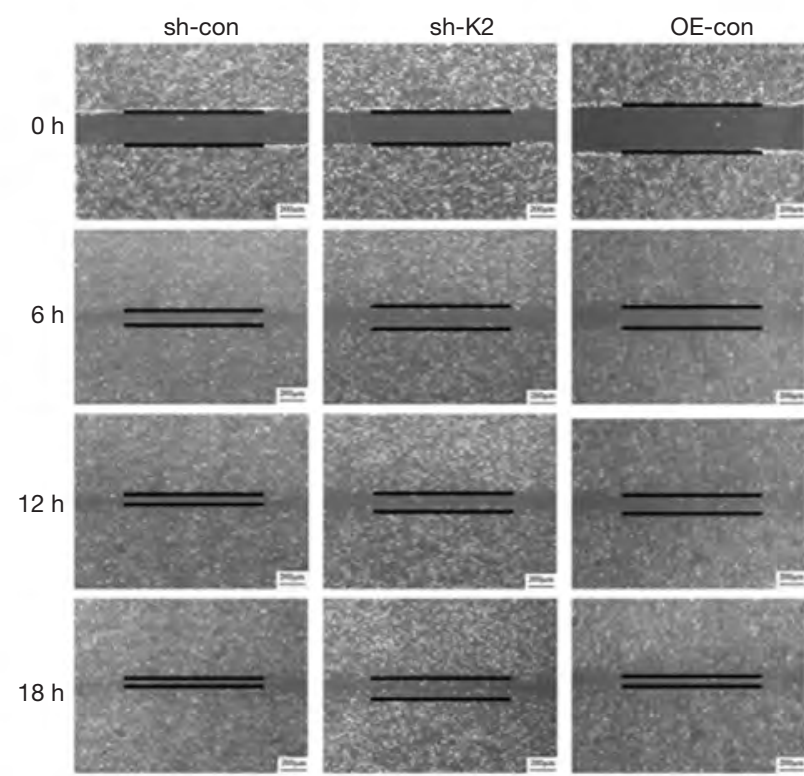
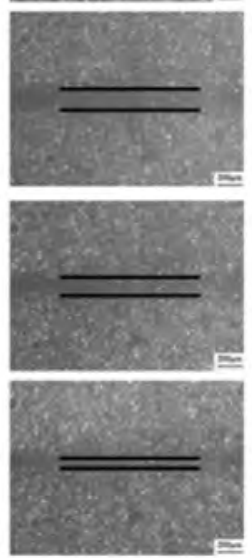
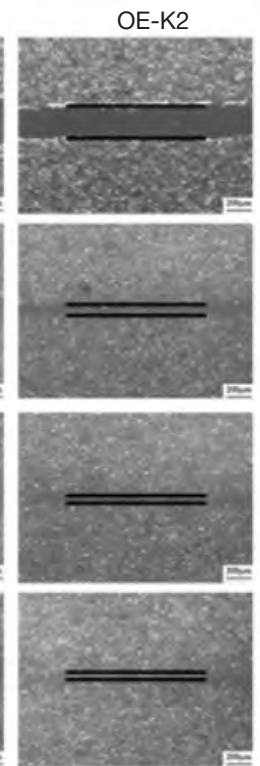

B

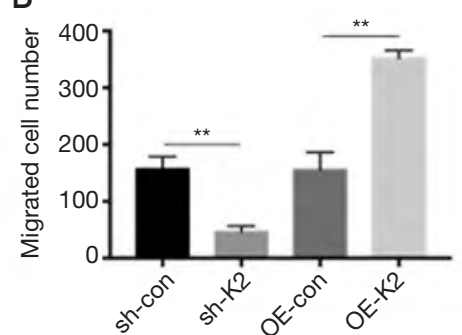

C

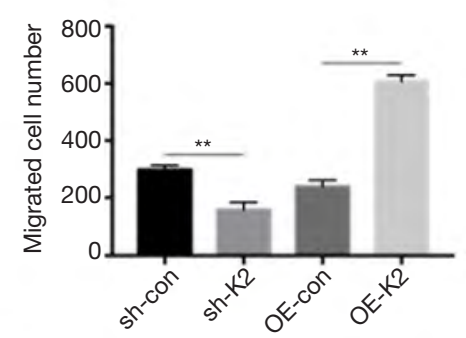

E

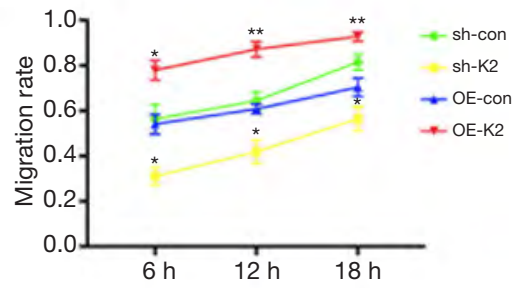

Figure 2 Kindlin-2 regulates migration of 3T3-L1 preadipocytes. (A) Transwell assays on 3T3-L1 preadipocytes after kindlin-2 knockdown and overexpression. The cells were stained with crystal violet. Scale bar $=200 \mu \mathrm{m}$. (B,C) The number of transmigrated cells at 24 and $48 \mathrm{~h}$. (D) In vitro wound healing assays at 6, 12, and $18 \mathrm{~h}$. Scale bar $=200 \mu \mathrm{m}$. (E) The migration rate of 3T3-L1 preadipocytes after kindlin-2 knockdown and overexpression. * $\mathrm{P}<0.05$; **, $\mathrm{P}<0.01$.

(Figure 5B). The percentage of wound area in the kindlin-2 $(+/-)$ mice on days 1-10 was significantly lower than that of the WT mice $(\mathrm{n}=6, \mathrm{P}<0.05)$ (Figure 5C).

The expression of leptin and adiponectin in wound tissues of the kindlin-2 (+/-) mice extracted on day 7 was significantly reduced compared with that of the WT mice $(\mathrm{n}=6, \mathrm{P}<0.01)$ (Figure 5D,E). In order to further explore whether kindlin-2 affects wound healing by regulating adipogenesis, western blotting was performed to analyze the protein levels of adipogenic markers, PPAR $\gamma, \mathrm{C} / \mathrm{EBP} \alpha$, and FABP4 in wound tissues on day 7. Compared with the WT mice, the expression of adipogenic markers $\operatorname{PPAR} \gamma$,
$\mathrm{C} / \mathrm{EBP} \alpha$, and FABP4 in the kindlin-2 (+/-) group was significantly reduced, which indicated that downregulation of kindlin-2 inhibited the adipogenesis of wound healing $(\mathrm{n}=6, \mathrm{P}<0.01)$ (Figure $5 F, G)$.

We further isolated the stromal vascular fraction (SVF) of inguinal adipose tissue from WT and kindlin-2 (+/-) mice and induced adipogenic differentiation in vitro. Oil Red $\mathrm{O}$ staining revealed that downregulation of kindlin-2 inhibited SVF adipogenic differentiation $(\mathrm{n}=6$, $\mathrm{P}<0.01$ ) (Figure $5 H, I$ ). Consistently, the protein levels of adipogenic markers, including $\mathrm{PPAR} \gamma, \mathrm{C} / \mathrm{EBP} \alpha$, and FABP4, were all dramatically reduced in SVF of kindlin-2 
A

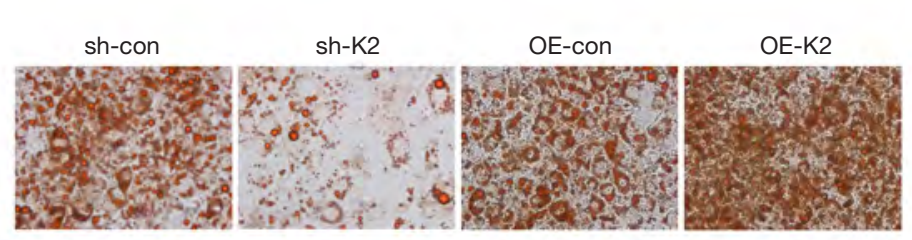

C

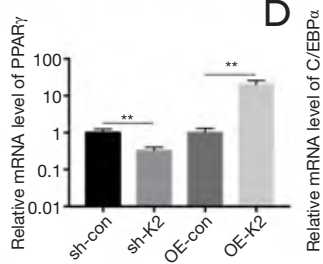

$\mathrm{H}$
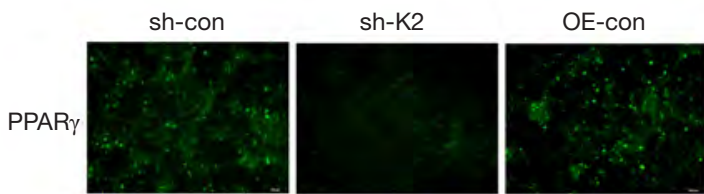

DAPI
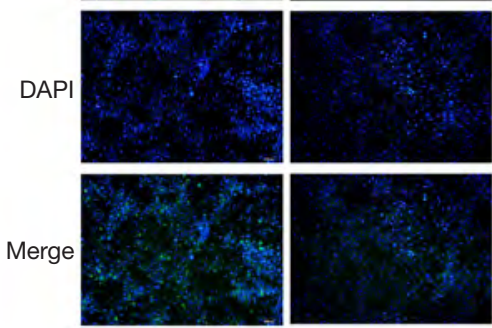

J

sh-con

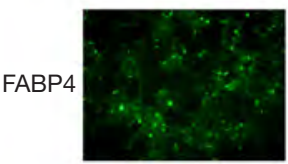

sh-K2
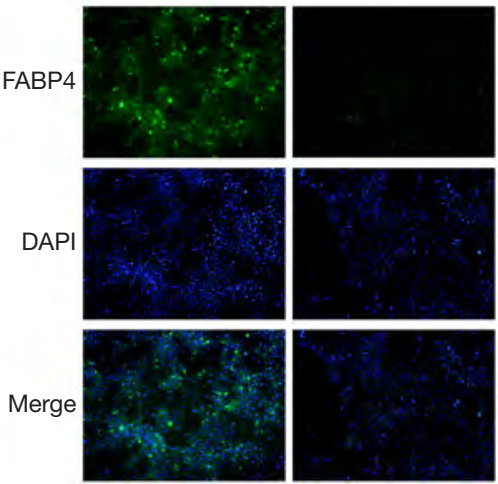

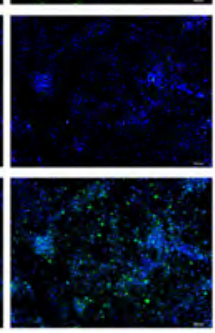

OE-con
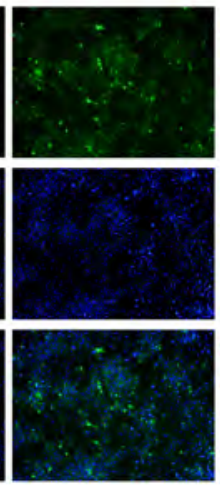

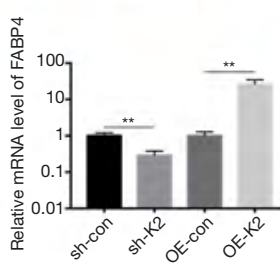

E-K2
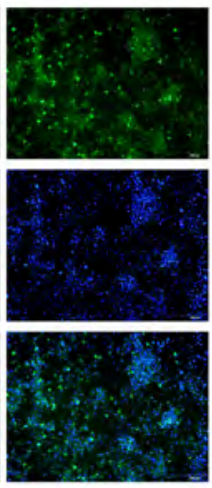

OE-K2
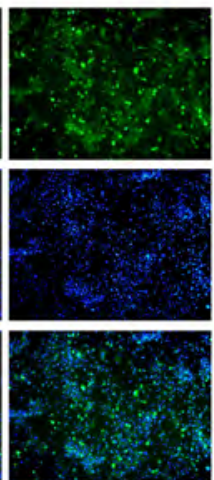

B

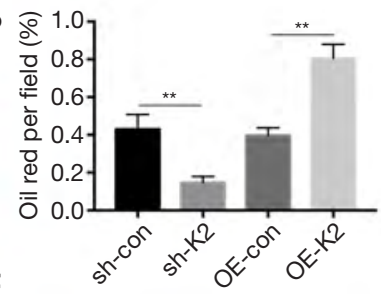

$\mathrm{F}$
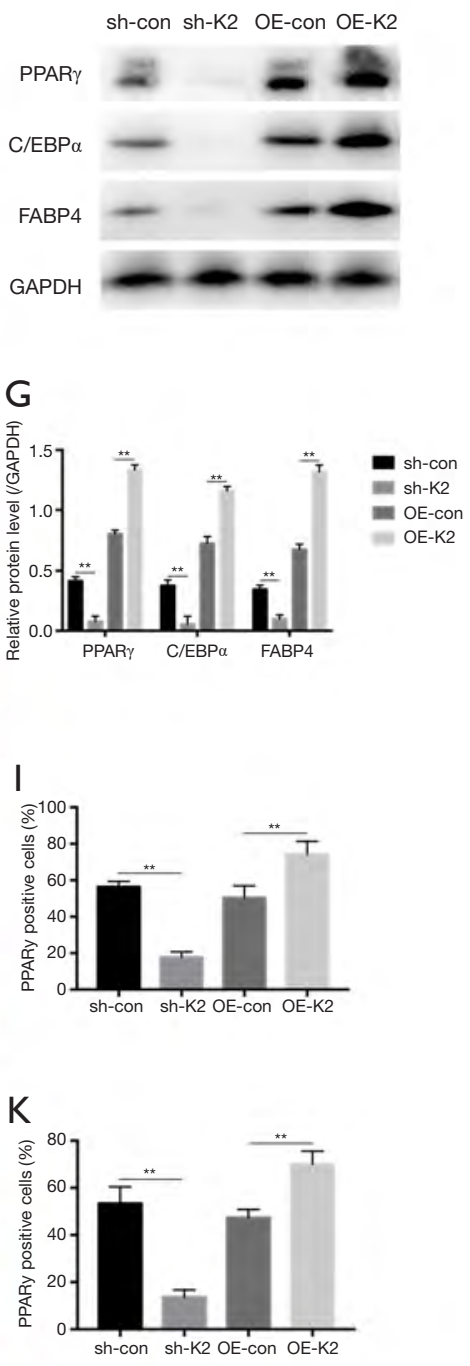

Figure 3 Kindlin-2 regulates adipogenic differentiation of 3T3-L1 preadipocytes. (A) In vitro adipogenesis differentiation and Oil Red O staining quantification of kindlin-2-knockdown cells, knockdown control cells, kindlin-2-overexpressing cells, and overexpressing control cells. Magnification: 200x. (B) Quantification of the total areas of Oil Red O-positive staining per macroscopic field. (C,D,E) RT-PCR analysis for the expression of adipogenic markers PPAR $\gamma, \mathrm{C} / \mathrm{EBP} \alpha$, and FABP4 after adipogenic differentiation induction. (F) Western blotting analysis for PPAR $\gamma, \mathrm{C} / \mathrm{EBP} \alpha$, and FABP4. (G) Quantification for protein levels of PPAR $\gamma, \mathrm{C} / \mathrm{EBP} \alpha$, and FABP4 relative to that of GAPDH. (H) Immunofluorescence staining with DAPI and PPAR $\gamma$. Scale bar $=200 \mu \mathrm{m}$. (I) Quantification of the percentages of PPAR $\gamma$ positive cells among total cells. (J) Immunofluorescence staining with DAPI and FABP4. Scale bar $=200 \mu \mathrm{m}$. (K) Quantification of the percentages of FABP4-positive cells among total cells. ${ }^{* *}, \mathrm{P}<0.01$. RT-PCR, real-time polymerase chain reaction; PPAR $\gamma$, proliferatoractivated receptor $\gamma$; C/EBP $\alpha$, CCAAT/enhancer-binding protein $\alpha$; FABP4, fatty acid-binding protein 4; GAPDH, glyceraldehyde phosphate dehydrogenase. 
A

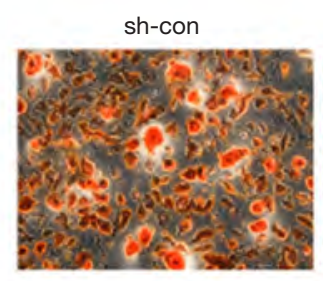

C

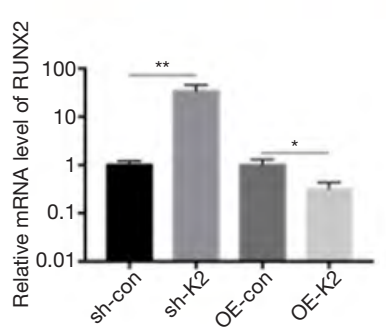

sh-K2

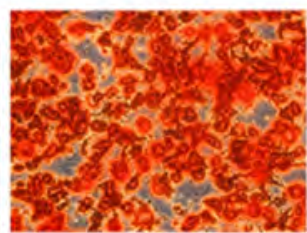

D

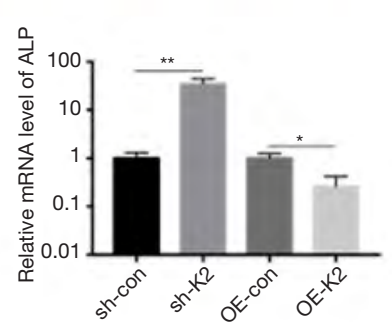

OE-con

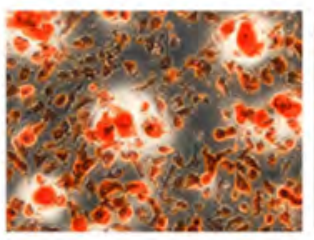

$E$
B

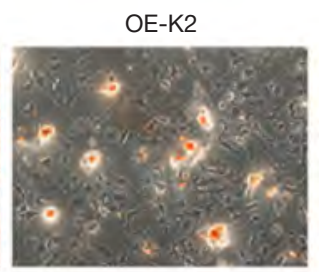

$\mathrm{F}$

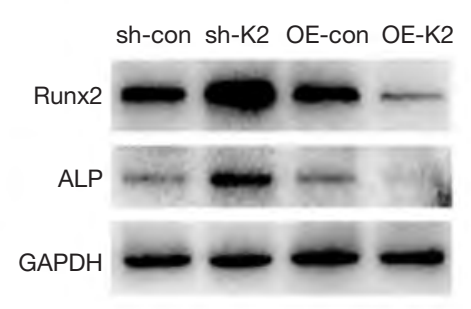

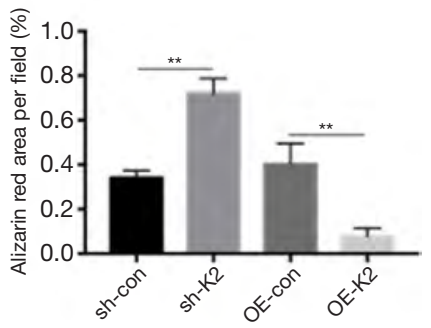

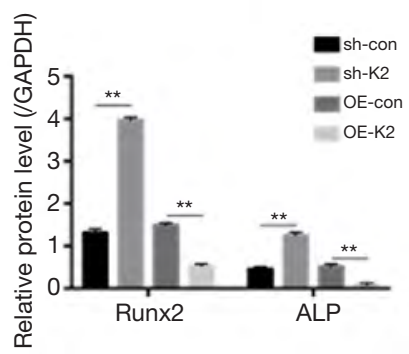

Figure 4 Kindlin-2 regulates osteogenic differentiation of 3T3-L1 preadipocytes. (A) In vitro osteogenic differentiation and Alizarin Red staining quantification of kindlin-2-knockdown cells, knockdown control cells, kindlin-2-overexpressing cells, and overexpressing control cells. Magnification: 200x. (B) Quantification of the total areas of Alizarin Red-positive staining per macroscopic field. (C,D) RT-PCR analysis for the expression of osteogenic markers ALP and Runx2 after osteogenic differentiation induction. (E) Western blotting analysis for ALP and Runx2. (F) Quantification for protein levels of ALP and Runx2 relative to that of GAPDH. *, P<0.05; **, P<0.01. RT-PCR, realtime polymerase chain reaction; ALP, alkaline phosphatase; Runx2, Runt-related transcription factor 2; GAPDH, glyceraldehyde phosphate dehydrogenase.

(+/-) mice compared with those of WT mice $(\mathrm{n}=6, \mathrm{P}<0.01)$ (Figure 57,K).

\section{Effect of the inbibition of adipogenesis on wound healing}

To further investigate the effect inhibited adipogenesis on wound healing, we observed the inflammatory response of wounds on days 1, 3, and 7 by (HE) staining. On day 1 , a large number of inflammatory cells infiltrated around the wound of the WT mice, whereas the infiltration of inflammatory cells in kindlin-2 (+/-) mice was significantly reduced. On day 3 , both groups showed a decreasing trend in inflammatory response, and the infiltration of inflammatory cells in kindlin-2 (+/-) mice was significantly less than that of the WT mice. On day 7, the number of inflammatory cells in both groups was significantly reduced compared to that on day 1 and 3 , but there was no significant difference between the two groups $(\mathrm{n}=6, \mathrm{P}<0.01)$ (Figure 6A,B).

CD31 IHC staining showed the angiogenesis of wounds on days 3, 5, and 7. The number of new blood vessels within the granulation tissue in the kindlin-2 (+/-) mice was significantly decreased compared with that in the WT mice $(\mathrm{n}=6, \mathrm{P}<0.01)$ (Figure 6C,D).

Masson staining in the wounds of WT mice showed a more collagen-rich wound bed, while a sparse collagen deposition was noticeable in the wounds of kindlin-2 (+/-) wound beds on days 3,5 , and $7(\mathrm{n}=6, \mathrm{P}<0.05)$ (Figure $6 E, F)$.

The contraction ability of wounds was assessed by $\alpha$-smooth muscle actin ( $\alpha$-SMA) IHC staining on days 3 , 5 , and 7. The area of $\alpha$-SMA-positive staining in kindlin-2 $(+/-)$ mice was significantly decreased compared with that in WT mice $(\mathrm{n}=6, \mathrm{P}<0.05)$ (Figure 6G,H).

\section{Kindlin-2 regulated adipogenic differentiation through PI3K/AKT/mTOR signaling pathway}

According to the data mining strategy described in Figure $7 A, 424$ genes on the pubmed2ensembl database were found that were related to adipogenic differentiation and adipogenesis. The protein-protein interaction network of the 424 genes and KINDLIN-2 were demonstrated by 
A

$+13 \mathrm{bp} / \mathrm{wt}$

aacatgaagtatgtgaaggtgaaagtgaacttTTAAAGTGAACTTctetgaccgagtcttcaaggctgtgtetgaca

$+20 \mathrm{bp} / \mathrm{wt}$

atgtgaaggtgaaagtgaacttetctgaccgaAAGTGAACTTCTCTGACCGAgtettcaaggetgtgtetgacatctgcaagac

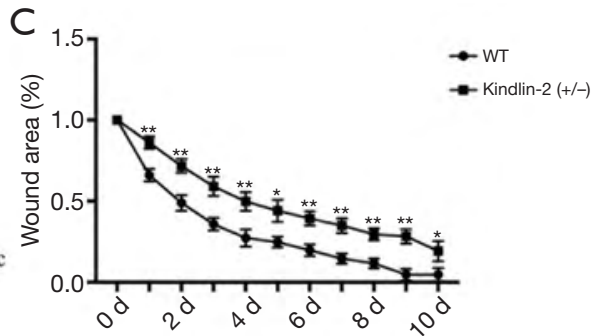

B

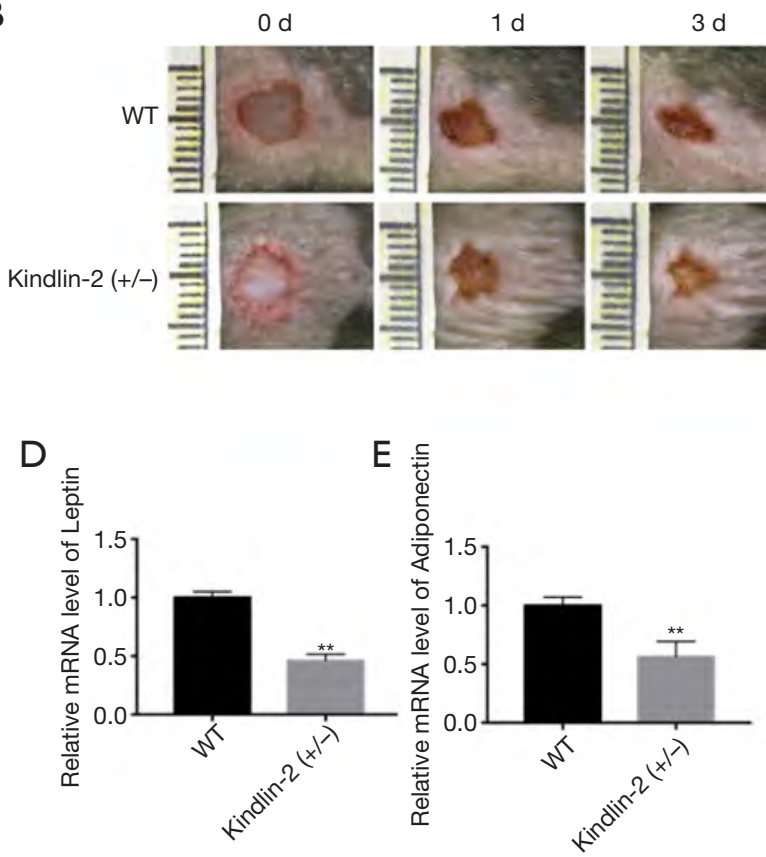

$\mathrm{H}$
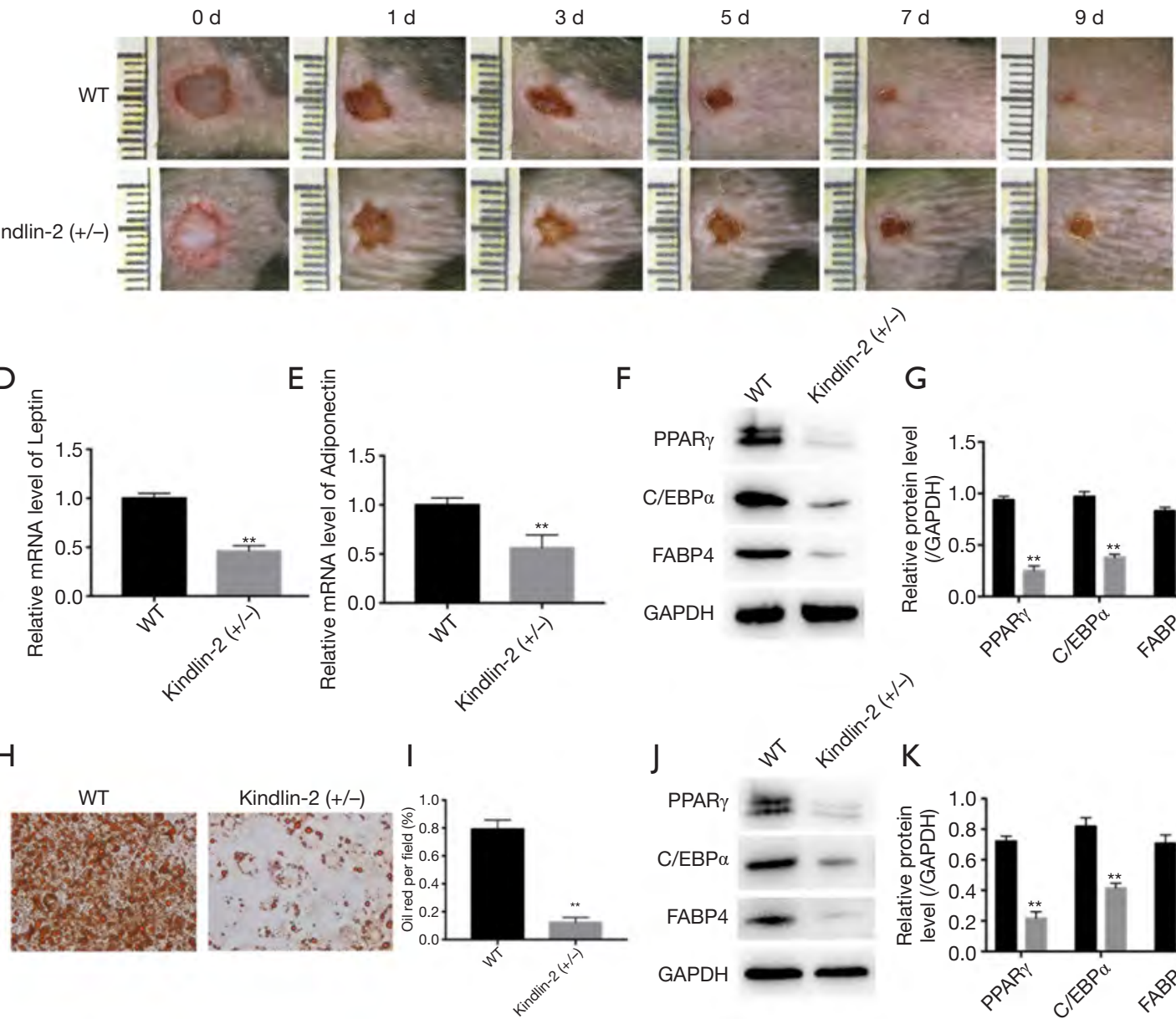

G

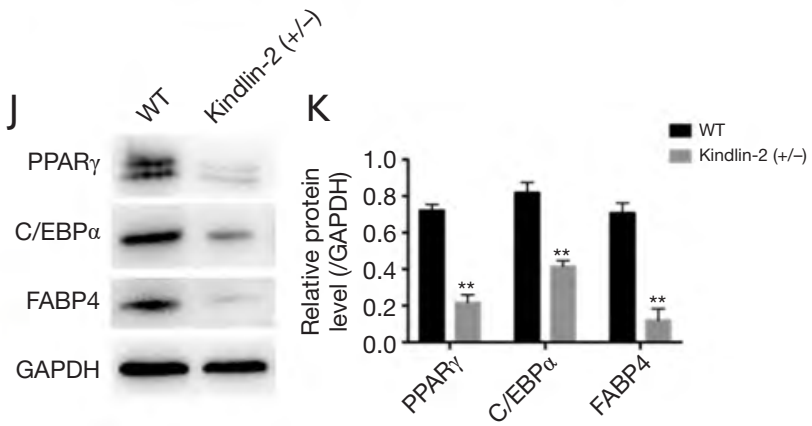

Figure 5 Downregulation of kindlin-2 inhibits adipogenesis in vivo. (A) DNA amplification and sequencing of the tail of transgenic mice. (B) Representative wound images at days $0,1,3,5$, 7, and 9 postoperation. (C) The wound healing rate of kindlin-2 (+/-) and WT mice. (D and E) RT-PCR analysis for the expression of adipokines, leptin and adiponectin, in the wound tissues on day 7 of kindlin-2 (+/-) and WT mice. (F) Western blotting analysis for PPAR $\gamma, \mathrm{C} / \mathrm{EBP} \alpha$, and FABP4 in wound tissues on day 7 of the kindlin-2 (+/-) and WT mice. (G) Quantification for protein levels of PPAR $\gamma, \mathrm{C} / \mathrm{EBP} \alpha$, and FABP4 relative to that of GAPDH. (H) In vitro adipogenesis differentiation and Oil Red O staining quantification of the SVF of inguinal adipose tissue from WT and kindlin-2 (+/-) mice. Magnification: 200×. (I) Quantification of the total areas of Oil Red O-positive staining per macroscopic field. (J) Western blotting analysis for PPAR $\gamma$, C/EBP $\alpha$, and FABP4 in SVF of WT and kindlin-2 (+/-) mice. (K) Quantification for protein levels of PPAR $\gamma$, C/EBP $\alpha$, and FABP4 relative to that of GAPDH. * $\mathrm{P}<0.05$; **, $\mathrm{P}<0.01$. RT-PCR, real-time polymerase chain reaction; PPAR $\gamma$, proliferator-activated receptor $\gamma$; $\mathrm{C} / \mathrm{EBP} \alpha$, CCAAT/ enhancer-binding protein $\alpha$ FABP4, fatty acid-binding protein 4; GAPDH, glyceraldehyde phosphate dehydrogenase; SVF, stromal vascular fraction. 
A

WT

Day 1

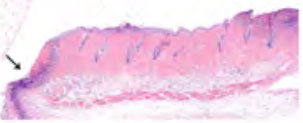

Day 3
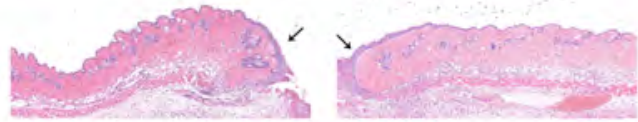

Day 7
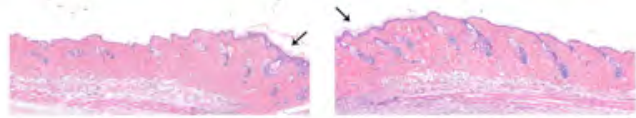

B

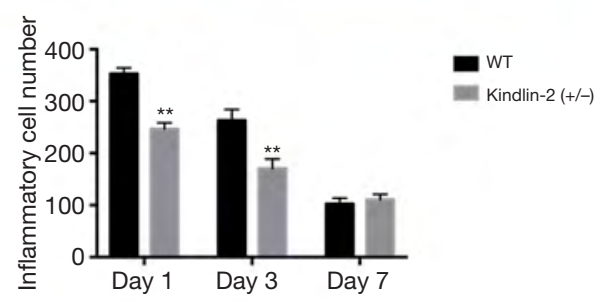

E
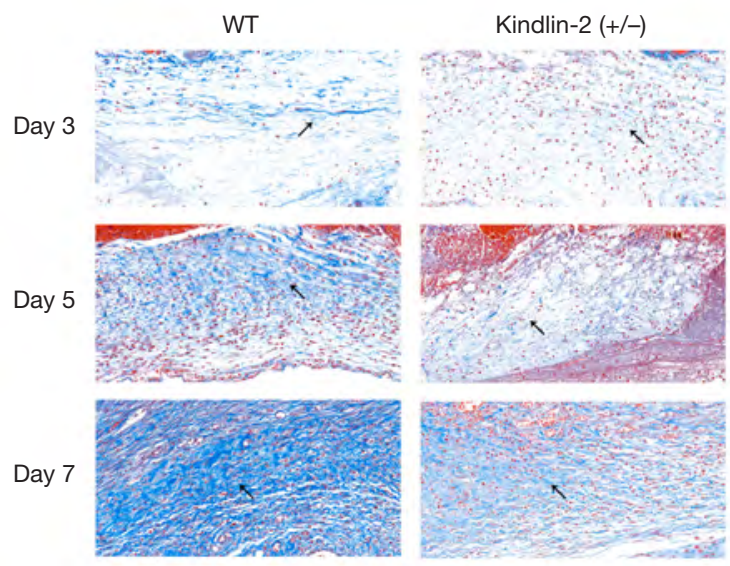

$\mathrm{F}$

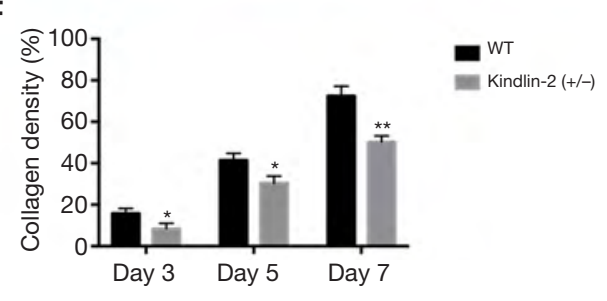

C

WT

Kindlin-2 (+/-)

Day 3
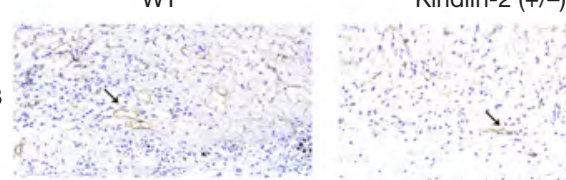

Day 5

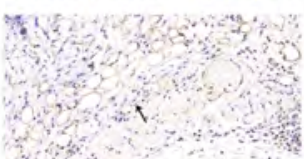

Day 7

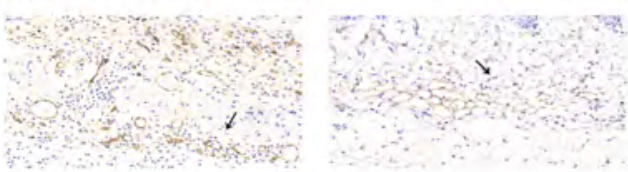

D

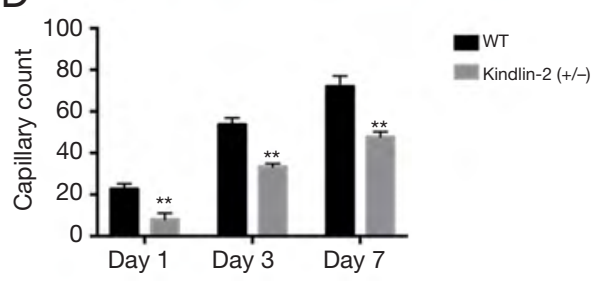

G
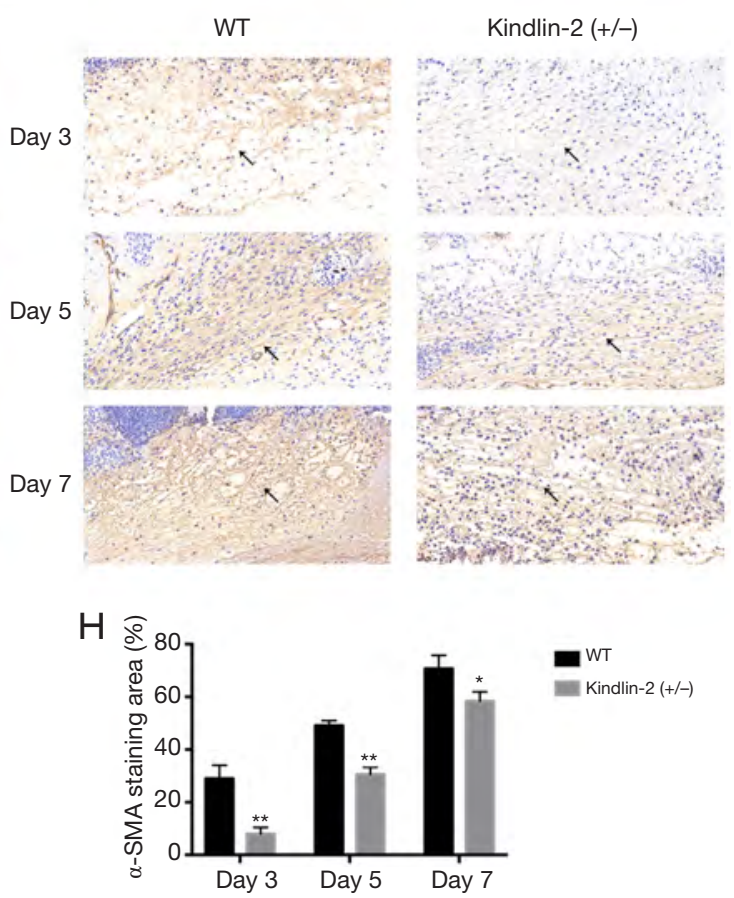

Figure 6 Effect of inhibition of adipogenesis on wound healing. (A) The inflammatory response of wounds on days 1,3 , and 7 showed by (HE) staining. Scale bar $=100 \mu \mathrm{m}$. (B) Quantitative analysis of inflammatory cells infiltrated around the wound. (C) CD31-positive new blood vessels by CD31 IHC staining within the granulation tissue of WT and kindlin-2 (+/-) mice wounds on days 3, 5, and 7. Scale bar =50 $\mu \mathrm{m}$. (D) Quantitative analysis of CD31-positive vessels. (E) Collagen deposition analyzed by Masson staining on days 3, 5, and 7. Scale bar =50 $\mu$ m. (F) Quantitative analysis of collagen deposition. (G) $\alpha$-SMA staining of WT and kindlin-2 (+/-) wounds on days 3, 5, and 7. Scale bar =50 $\mu$ m. $(\mathrm{H})$ Quantitative analysis of $\alpha$-SMA-positive area. * $\mathrm{P}<0.05$; **, $\mathrm{P}<0.01$. HE, hematoxylin and eosin; IHC, immunohistochemical staining; WT, wide type; $\alpha$-SMA, $\alpha$-smooth muscle actin. 
A

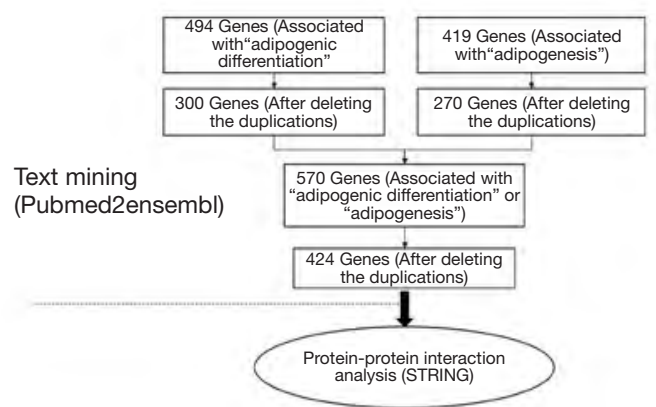

B

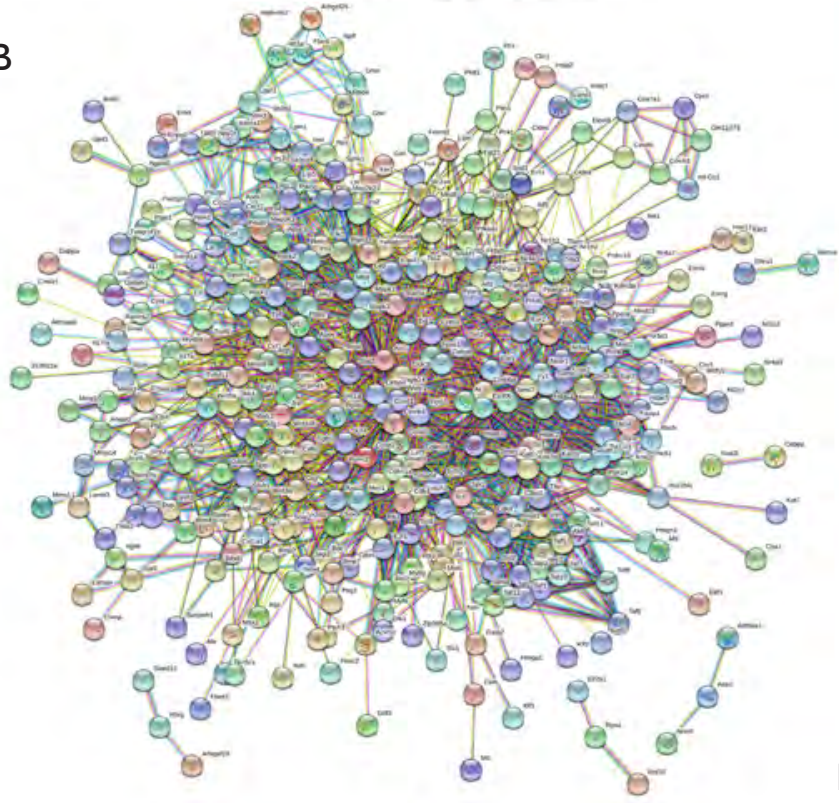

D

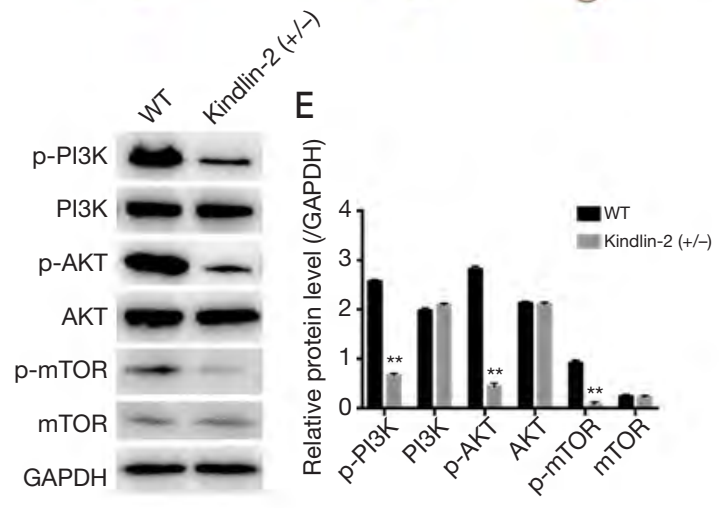

C

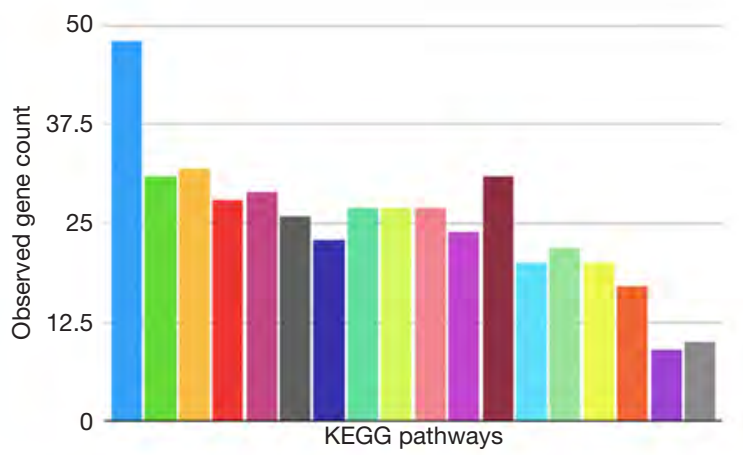

EI3K-Akt signaling pathway

E FoxO signaling pathway

Wnt signaling pathway
AMPK signaling pathway

AMPK signaling pathway
Signaling pathways regulating pluripotency of stem cells

AGE-RAGE signaling pathway in

Adipocytokine signaling pathway
Non-alcoholic fatty liver disease (NAFLD)

mTOR

Hippo signaling pathway

Insulin signaling pathway

MAPK signaling pathway

TNF signaling pathway

Apelin signaling pathway

HIF-1 signaling pathway

TGF-beta signaling pathway

Notch signaling pathway

NF-kappa B signaling pathway

\section{$\mathrm{F}$}

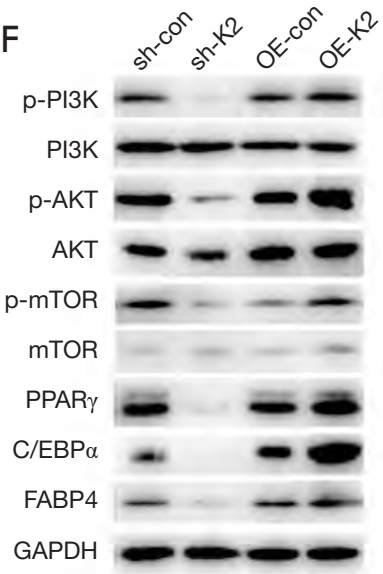

\section{G}

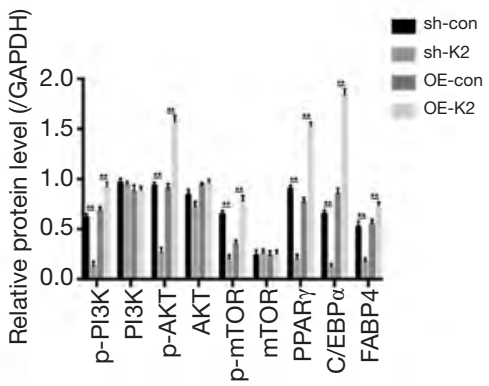



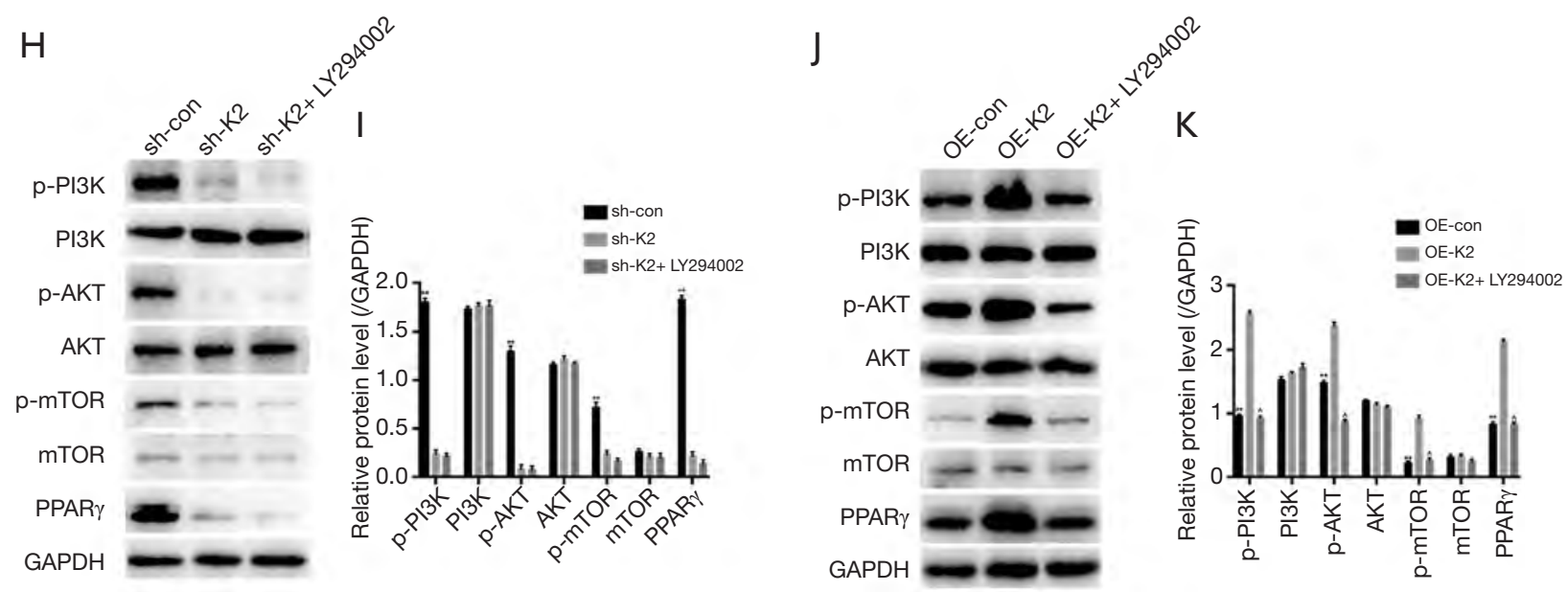

Figure 7 Kindlin-2 regulates adipogenic differentiation through PI3K/AKT/mTOR signaling pathway. (A) Overall data mining process. A total of 424 genes were found to be related to adipogenic differentiation through a pubmed2ensembl database text mining process; proteinprotein interaction analysis was then performed by using STRING. (B) The protein-protein interaction network of the 425 targeted genes using STRING. (C) Pathways highly related to adipogenic differentiation by STRING. (D,E) Western blotting analysis and quantification for the protein levels of p-PI3K, AKT, p-AKT, mTOR, and p-mTOR in wound tissues of WT and kindlin-2 (+/-) mice. (F,G) Western blotting analysis and quantification for the protein levels of p-PI3K, AKT, p-AKT, mTOR, p-mTOR, PPAR $\gamma, \mathrm{C} / \mathrm{EBP} \alpha$, and FABP4 in kindlin-2-knockdown cells, kindlin-2-overexpressing cells, and their corresponding control cells after adipogenic differentiation induction. $(\mathrm{H}, \mathrm{I})$ Western blotting analysis and quantification for the protein levels of p-PI3K, AKT, p-AKT, mTOR, p-mTOR, and PPAR $\gamma$ in kindlin2-knockdown cells, the corresponding cells, and kindlin-2-knockdown + LY294002 cells after adipogenic differentiation induction. (J,K) Western blotting analysis and quantification for the protein levels of p-PI3K, AKT, p-AKT, mTOR, p-mTOR, and PPAR $\gamma$ in kindlin-2overexpressing cells, the corresponding cells, and kindlin-2-overexpressing + LY294002 cells after adipogenic differentiation induction. **, $\mathrm{P}<0.01$; ^, $\mathrm{P}<0.01$ vs. sh-K2. PI3K, phosphatidylinositol 3-kinase; AKT, protein kinase B; mTOR, mammalian target of rapamycin; WT, wide type; $\operatorname{PPAR} \gamma$, proliferator-activated receptor $\gamma$; $\mathrm{C} / \mathrm{EBP} \alpha$, CCAAT/enhancer-binding protein $\alpha$; FABP4, fatty acid-binding protein 4; GAPDH, glyceraldehyde phosphate dehydrogenase.

STRING (Figure 7B). The pathways highly related to adipogenic differentiation included PI3K-AKT signaling pathway, MAPK signaling pathway, Wnt signaling pathway, FoxO signaling pathway, and other pathways, among which PI3K-AKT signaling pathway showed the highest correlation and was thus selected as the target pathway for this study (Figure 7C).

To determine if kindlin-2 regulates adipogenic differentiation through $\mathrm{PI} 3 \mathrm{~K} / \mathrm{AKT} / \mathrm{mTOR}$ signaling pathway in vivo, western blotting was performed to analyze the protein level of upstream and downstream molecules of $\mathrm{PI} 3 \mathrm{~K} / \mathrm{AKT} / \mathrm{mTOR}$ signaling pathway of the wound tissues extracted from the WT and kindlin-2 (+/-) mice on day 7 . Compared with the levels in the WT mice, the protein levels of p-PI3K, p-AKT, and p-mTOR in the kindlin-2 $(+/-)$ group were reduced, indicating that downregulation of kindlin-2 inhibits PI3K/AKT/mTOR signaling pathway in wounds $(\mathrm{n}=6, \mathrm{P}<0.01)$ (Figure $7 D, E)$.
In vitro, we induced adipogenic differentiation of 3T3L1 preadipocytes in kindlin-2-knockdown cells, knockdown control cells, kindlin-2-overexpressing cells, and overexpressing control cells by the method described above. Western blotting was then performed to analyze the protein levels of the molecules of PI3K/AKT/mTOR signaling pathway and adipogenic markers. Consistent with in vivo results, the protein levels of p-PI3K, p-AKT, p-mTOR, $\mathrm{PPAR} \gamma, \mathrm{C} / \mathrm{EBP} \alpha$, and FABP4 were dramatically decreased in kindlin-2-knockdown cells compared with those in the control group and increased in kindlin-2-overexpressing cells compared with those in the corresponding control group $(\mathrm{P}<0.01)$ (Figure $7 F, G)$.

Next, we treated knockdown and overexpressing 3T3L1 preadipocytes with the PI3K inhibitor, LY294002, and then induced adipogenic differentiation. Western blotting showed that the protein levels of p-PI3K, p-AKT, p-mTOR, and PPAR $\gamma$ were significantly decreased in the kindlin-2- 
knockdown cells and kindlin-2-knockdown + LY294002 cells compared with those in the corresponding group. However, there was no significant difference between the kindlin-2-cells and the kindlin-2-knockdown + LY294002 cells (Figure 7H,I). Conversely, overexpression of kindlin-2 markedly increased the p-PI3K, p-AKT, p-mTOR, and PPAR $\gamma$ expression levels, demonstrating that kindlin-2 could activate the PI $3 \mathrm{~K} / \mathrm{AKT} / \mathrm{mTOR}$ pathway and promote adipogenic differentiation. However, LY294002 significantly reversed these effects. Taken together, these results confirmed the role of kindlin-2 in regulating adipogenic differentiation through $\mathrm{PI} 3 \mathrm{~K} / \mathrm{AKT} / \mathrm{mTOR}$ signaling pathway $(\mathrm{P}<0.01)$ (Figure $7 \mathcal{F}, \mathrm{K})$.

\section{Discussion}

Adipose tissue has been proven to play a crucial role in wound healing by regulating nutrient metabolism, secreting cytokines, and directing differentiation (5). However, whether a target exists that promotes adipogenesis, thereby promoting wound healing, remains unclear. Kindlin-2, a component of cell-extracellular matrix adhesions, activates integrin by binding with the cytoskeletal protein, talin and regulates cell adhesion, migration, proliferation, and differentiation (21). Recently, evidence has emerged that kindlin-2 holds great potential in wound healing and cell differentiation (17-19). The present study identified kindlin-2 as a key determinant of the differentiation of 3T3-L1 preadipocytes in wound healing and delineated the underlying signaling mechanism.

To begin, we verified the effect of kindlin-2 on the biological function of 3T3-L1 preadipocytes and found that kindlin-2 is positively correlated with the adhesion and migration of 3T3-L1 preadipocytes. Kindlins bind to $\alpha$-actin, migflin, or integrin-linked kinase through the FERM domain and adhere to $\beta$ cytoplasmic chain to activate integrin, leading to actin remodeling, cell migration, and the formation of plate-like pseudopods (22). Our study demonstrated that downregulation of kindlin-2 inhibits adipogenic differentiation and promotes osteogenic differentiation both in cultured 3T3-L1 preadipocytes and kindlin-2 (+/-) mice, whereas upregulation of kindlin-2 promotes 3T3-L1 preadipocyte adipogenic differentiation and inhibits osteogenic differentiation. The important role of kindlin-2 in determining cell processes has been reported in recent years. Wu et al. and Guo et al. demonstrated that depletion of kindlin-2 in MSCs inhibits cartilage formation, damages bone development, induces adipogenesis, and inhibits osteogenesis through controlling Yes-associated protein 1 (YAP1) and Taffazzin (TAZ) which are key signaling intermediates that link adhesive and mechanical cues to MSC differentiation $(17,19)$. In iPSC-MSCs, overexpression of kindlin-2 leads to increased proliferation and decreased apoptosis, and inhibits their differentiation into osteocytes, adipocytes, and chondrocytes (18). Noticeably, we observed that kindlin-2 has the opposite effect of inducing adipogenesis and osteogenesis in 3T3L1 preadipocytes. In vivo, we verified that downregulation of kindlin-2 reduces the level of leptin and adiponectin which are two effective osteogenesis inhibitors. Therefore, the reduction of leptin and adiponectin may contribute to increased osteogenic differentiation (23-26).

To illustrate the molecular mechanism by which kindlin-2 controls the cell fate decision of 3T3-L1 preadipocytes, we used computational biology and identified PI3K/AKT/ mTOR signaling pathway as having the highest correlation with adipogenesis as the target pathway. We demonstrated that kindlin-2 regulates adipogenic differentiation through PI3K/AKT/mTOR signaling pathway. First, downregulation of kindlin-2 markedly reduced the levels of $\mathrm{p}-\mathrm{PI} 3 \mathrm{~K}, \mathrm{p}-\mathrm{AKT}$, and $\mathrm{p}-\mathrm{mTOR}$, and the adipogenic markers both in vitro and in vivo, whereas overexpression of kindlin-2 promoted the expression levels of p-PI3K, $\mathrm{p}-\mathrm{AKT}$, and p-mTOR, and the adipogenic markers, indicating that kindlin-2 controls the level of PI3K/ AKT/mTOR signaling pathway as an upstream molecule. However, LY294002, a specific PI3K inhibitor, significantly reversed the effects of overexpressing kindlin-2; that is, the inhibition of adipogenic differentiation. Collectively, these results confirmed that kindlin-2 regulates adipogenic differentiation through PI3K/AKT/mTOR signaling pathway. Studies have reported that adipogenesis can be mediated, at least in part, by $\mathrm{PI} 3 \mathrm{~K} / \mathrm{AKT} / \mathrm{mTOR}$ signaling pathway (27-29). Decreased expression of mTOR and AKT induced by kindlin-2 decrease could lead to adipose tissue reduction in mutant mice, indicating that these signaling pathways are essential for the development of adipose tissue (30-32). AKT signaling is necessary for adipogenesis, with AKT1 being necessary for adipogenic differentiation in 3T3-L1 preadipocytes and embryonic fibroblasts (33-35). Depletion of mTOR reduces lipid accumulation and inhibits adipocyte differentiation, and PPAR $\gamma$ can reverse the impaired adipogenesis caused by mTOR deletion (30). In addition, the mTOR-specific inhibitor, rapamycin, can inhibit adipogenic differentiation (36-38).

In this study, we demonstrated that the downregulation 
of kindlin-2 inhibited wound healing. The levels of adipokines, leptin, and adiponectin, were significantly reduced in kindlin-2 (+/-) mice, suggesting that deficient wound healing may be related to the inhibitory effect of kindlin-2 on adipogenesis. Leptin, the first protein discovered to be secreted by adipocytes, plays an important role in wound healing by promoting angiogenesis, reepithelialization, collagen synthesis, and proliferation of keratinocytes, and fibroblasts (39-43). Another adipokine, adiponectin, is a potent mediator in the regulation of wound healing. Shibata et al. demonstrated that wound closure was significantly delayed in adiponectin-deficient mice, while keratinocyte proliferation and migration were also impaired in adiponectin-deficient mice (44). Jin $e t a l$. showed that adiponectin promotes preadipocyte proliferation and migration (45). Furthermore, PPAR $\gamma$ and $\mathrm{C} / \mathrm{EBP} \alpha$, which are key transcriptional regulators, were significantly reduced in kindlin-2 (+/-) mice, suggesting poor adipogenesis which contributes to delayed wound healing after the downregulation of kindlin-2. Similarly, the results of analyzing SVF extracted from adipose tissue further confirmed that downregulation of kindlin-2 inhibited adipogenic differentiation in mice.

To determine how the inhibition of adipogenic differentiation by kindlin-2 affects wound healing, we observed the suppression of the key steps in wound healing, including inflammation, angiogenesis, collagen remodeling, and wound contraction. In each stage of wound healing, various cell types including inflammatory cells, vascular endothelial cells, fibroblasts, etc. play different roles. Downregulation of kindlin-2 has been proven to impair integrin activation, reducing the actin network, affecting cell migration, and destroying the adhesion function between cells and extracellular matrix $(14,15,46,47)$. Previous studies have shown that kindlin-2 regulates adhesion and migration of NHFs and endothelial cells $(15,48)$. Thus, we speculated that downregulation of kindlin-2 may inhibit the migration and adhesion of inflammatory cells and myofibroblasts, thereby inhibiting inflammation, collagen remodeling, and wound contraction in wound healing. The specific mechanism needs to be further studied, however.

\section{Conclusions}

Our studies have identified the key role of kindlin-2 in the differentiation of 3T3-L1 preadipocytes and wound healing, as well as the underlining mechanism. We found that kindlin-2 regulates the adipogenic differentiation of 3T3-
L1 preadipocytes through $\mathrm{PI} 3 \mathrm{~K} / \mathrm{AKT} / \mathrm{mTOR}$ signaling pathway. Downregulation of kindlin-2 inhibits wound healing and adipogenesis in mice. Given the importance of adipogenesis in 3T3-L1 preadipocytes, our findings may provide a novel therapeutic approach in wound healing.

\section{Acknowledgments}

Funding: This work was supported by the National Natural Science Foundation of China (No. 81671915).

\section{Footnote}

Reporting Checklist: The authors have completed the ARRIVE reporting checklist. Available at http://dx.doi. org/10.21037/atm-21-176

Data Sharing Statement: Available at http://dx.doi. org/10.21037/atm-21-176

Conflicts of Interest: All authors have completed the ICMJE uniform disclosure form (available at http://dx.doi. org/10.21037/atm-21-176). The authors have no conflicts of interest to declare.

Ethical Statement: The authors are accountable for all aspects of the work in ensuring that questions related to the accuracy or integrity of any part of the work are appropriately investigated and resolved. Experiments were performed under a project license (No.: 2017-007) granted by Animal Ethics Committee of Zhongshan Hospital, in compliance with national guidelines for the care and use of animals.

Open Access Statement: This is an Open Access article distributed in accordance with the Creative Commons Attribution-NonCommercial-NoDerivs 4.0 International License (CC BY-NC-ND 4.0), which permits the noncommercial replication and distribution of the article with the strict proviso that no changes or edits are made and the original work is properly cited (including links to both the formal publication through the relevant DOI and the license). See: https://creativecommons.org/licenses/by-nc-nd/4.0/.

\section{References}

1. Patel S, Maheshwari A, Chandra A. Biomarkers for wound healing and their evaluation. J Wound Care 
2016;25:46-55.

2. Sen CK, Gordillo GM, Roy S, et al. Human skin wounds: a major and snowballing threat to public health and the economy. Wound Repair Regen 2009;17:763-71.

3. Fasshauer M, Bluher M. Adipokines in health and disease. Trends Pharmacol Sci 2015;36:461-70.

4. Franz A, Wood W, Martin P. Fat Body Cells Are Motile and Actively Migrate to Wounds to Drive Repair and Prevent Infection. Dev Cell 2018;44:460-70.e3.

5. Zwick RK, Guerrero-Juarez CF, Horsley V, et al. Anatomical, Physiological, and Functional Diversity of Adipose Tissue. Cell Metab 2018;27:68-83.

6. Schmidt BA, Horsley V. Intradermal adipocytes mediate fibroblast recruitment during skin wound healing. Development 2013;140:1517-27.

7. Shook BA, Wasko RR, Mano O, et al. Dermal Adipocyte Lipolysis and Myofibroblast Conversion Are Required for Efficient Skin Repair. Cell Stem Cell 2020;26:880-95.e6.

8. Nguyen A, Guo J, Banyard DA, et al. Stromal vascular fraction: A regenerative reality? Part 1: Current concepts and review of the literature. J Plast Reconstr Aesthet Surg 2016;69:170-9.

9. Guo J, Nguyen A, Banyard DA, et al. Stromal vascular fraction: A regenerative reality? Part 2: Mechanisms of regenerative action. J Plast Reconstr Aesthet Surg 2016;69:180-8.

10. Prunet-Marcassus B, Cousin B, Caton D, et al. From heterogeneity to plasticity in adipose tissues: site-specific differences. Exp Cell Res 2006;312:727-36.

11. Otto TC, Lane MD. Adipose development: from stem cell to adipocyte. Crit Rev Biochem Mol Biol 2005;40:229-42.

12. Cristancho AG, Lazar MA. Forming functional fat: a growing understanding of adipocyte differentiation. Nat Rev Mol Cell Biol 2011;12:722-34.

13. Larjava H, Plow E, Wu C. Kindlins: essential regulators of integrin signalling and cell-matrix adhesion. EMBO Rep 2008;9:1203-8.

14. Montanez E, Ussar S, Schifferer M, et al. Kindlin-2 controls bidirectional signaling of integrins. Genes Dev 2008;22:1325-30.

15. He Y, Esser P, Schacht V, et al. Role of kindlin-2 in fibroblast functions: implications for wound healing. J Invest Dermatol 2011;131:245-56.

16. Ying J, Luan W, Lu L, et al. Knockdown of the KINDLIN-2 Gene and Reduced Expression of Kindlin-2 Affects Vascular Permeability in Angiogenesis in a Mouse Model of Wound Healing. Med Sci Monit 2018;24:5376-83.
17. Wu C, Jiao H, Lai Y, et al. Kindlin-2 controls TGF- $\beta$ signalling and Sox 9 expression to regulate chondrogenesis. Nat Commun 2015;6:7531.

18. Moslem M, Eggenschwiler R, Wichmann C, et al. Kindlin-2 Modulates the Survival, Differentiation, and Migration of Induced Pluripotent CellDerived Mesenchymal Stromal Cells. Stem Cells Int 2017;2017:7316354.

19. Guo L, Cai T, Chen K, et al. Kindlin-2 regulates mesenchymal stem cell differentiation through control of YAP1/TAZ. J Cell Biol 2018;217:1431-51.

20. Baran J, Gerner M, Haeussler M, et al. pubmed2ensembl: a resource for mining the biological literature on genes. PloS One 2011;6:e24716.

21. Ma YQ, Qin J, Wu C, et al. Kindlin-2 (Mig-2): a co-activator of beta3 integrins. The J Cell Biol 2008;181:439-46.

22. Rognoni E, Ruppert R, Fässler R. The kindlin family: functions, signaling properties and implications for human disease. J Cell Sci 2016;129:17-27.

23. Elefteriou F, Takeda S, Ebihara K, et al. Serum leptin level is a regulator of bone mass. Proc Natl Acad Sci U S A 2004;101:3258-63.

24. Ducy $\mathrm{P}$, Amling $M$, Takeda $S$, et al. Leptin inhibits bone formation through a hypothalamic relay: a central control of bone mass. Cell 2000;100:197-207.

25. Zhang HQ, Wang LJ, Liu SH, et al. Adiponectin regulates bone mass in AIS osteopenia via RANKL/OPG and IL6 pathway. J Transl Med 2019;17:64.

26. Kajimura D, Lee H, Riley K, et al. Adiponectin regulates bone mass via opposite central and peripheral mechanisms through FoxO1. Cell Metab 2013;17:901-15.

27. Cai R, Tang G, Zhang Q, et al. A Novel lnc-RNA, Named lnc-ORA, Is Identified by RNA-Seq Analysis, and Its Knockdown Inhibits Adipogenesis by Regulating the PI3K/AKT/mTOR Signaling Pathway. Cells 2019;8:477.

28. Song F, Jiang D, Wang T, et al. Mechanical Stress Regulates Osteogenesis and Adipogenesis of Rat Mesenchymal Stem Cells through PI3K/Akt/GSK-

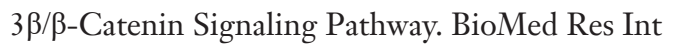
2017;2017:6027402.

29. Tang R, Ma F, Li W, et al. miR-206-3p Inhibits 3T3-L1 Cell Adipogenesis via the c-Met/PI3K/Akt Pathway. Int J Mol Sci 2017;18:1510.

30. Shan T, Zhang P, Jiang Q, et al. Adipocyte-specific deletion of mTOR inhibits adipose tissue development and causes insulin resistance in mice. Diabetologia 2016;59:1995-2004.

31. Shearin AL, Monks BR, Seale P, et al. Lack of AKT 
in adipocytes causes severe lipodystrophy. Mol Metab 2016;5:472-9.

32. Peng XD, Xu PZ, Chen ML, et al. Dwarfism, impaired skin development, skeletal muscle atrophy, delayed bone development, and impeded adipogenesis in mice lacking Akt1 and Akt2. Genes Dev 2003;17:1352-65.

33. Bae SS, Cho H, Mu J, et al. Isoform-specific regulation of insulin-dependent glucose uptake by Akt/protein kinase B. J Biol Chem 2003;278:49530-6.

34. Yun SJ, Kim EK, Tucker DF, et al. Isoform-specific regulation of adipocyte differentiation by Akt/protein kinase Balpha. Biochem Biophys Res Commun 2008;371:138-43.

35. Baudry A, Yang ZZ, Hemmings BA. PKBalpha is required for adipose differentiation of mouse embryonic fibroblasts. J Cell Sci 2006;119:889-97.

36. Cho HJ, Park J, Lee HW, et al. Regulation of adipocyte differentiation and insulin action with rapamycin. Biochem Biophys Res Commun 2004;321:942-8.

37. Gagnon A, Dods P, Roustan-Delatour N, et al. Phosphatidylinositol-3,4,5-trisphosphate is required for insulin-like growth factor 1-mediated survival of 3T3-L1 preadipocytes. Endocrinology 2001;142:205-12.

38. Yu T, Wang M, Wen Y, et al. Activation of mammalian target of rapamycin induces lipid accumulation in the diaphragm of ventilated rats and hypoxia-treated C2C12 cells. J Surg Res 2018;225:82-9.

39. Peelman F, Couturier C, Dam J, et al. Techniques: new pharmacological perspectives for the leptin receptor. Trends Pharmacol Sci 2006;27:218-25.

40. Marikovsky M, Rosenblum CI, Faltin Z, et al. Appearance of leptin in wound fluid as a response to injury. Wound

Cite this article as: Pan Y, Wang Q, Luan W, Shi Y, Liu J, Qi F. Kindlin-2 regulates the differentiation of 3T3-L1 preadipocytes: implications for wound healing. Ann Transl Med 2021;9(4):348. doi: 10.21037/atm-21-176
Repair Regen 2002;10:302-7.

41. Liapaki I, Anagnostoulis S, Karayiannakis A, et al. Burn wound angiogenesis is increased by exogenously administered recombinant leptin in rats. Acta Cir Bras 2008;23:118-24.

42. Liapakis IE, Anagnostoulis S, Karayiannakis AJ, et al. Recombinant leptin administration improves early angiogenesis in full-thickness skin flaps: an experimental study. In Vivo 2008;22:247-52.

43. Hekerman P, Zeidler J, Korfmacher S, et al. Leptin induces inflammation-related genes in RINm5F insulinoma cells. BMC Mol Biol 2007;8:41.

44. Shibata S, Tada Y, Asano Y, et al. Adiponectin regulates cutaneous wound healing by promoting keratinocyte proliferation and migration via the ERK signaling pathway. J Immunol 2012;189:3231-41.

45. Jin CE, Xiao L, Ge ZH, et al. Role of adiponectin in adipose tissue wound healing. Genet Mol Res 2015;14:8883-91.

46. Shi X, Ma YQ, Tu Y, et al. The MIG-2/integrin interaction strengthens cell-matrix adhesion and modulates cell motility. J Biol Chem 2007;282:20455-66.

47. Ren Y, Jin H, Xue Z, et al. Kindlin-2 inhibited the growth and migration of colorectal cancer cells. Tumour Biol 2015;36:4107-14.

48. Pluskota E, Ma Y, Bledzka KM, et al. Kindlin-2 regulates hemostasis by controlling endothelial cell-surface expression of ADP/AMP catabolic enzymes via a clathrindependent mechanism. Blood 2013;122:2491-9.

(English Language Editor: J. Gray) 


\section{Supplementary}

Table S1 Sequences of primers used for real-time polymerase chain reaction

\begin{tabular}{lll}
\hline Gene & FORWARD primer (5'-3') & REVERSE primer (5'-3') \\
\hline KINDLIN2 & CGAGGTTTCAAGGCGGCAAGAG & TTGGATGGCGTCACCTGTGCTG \\
PPARG & GAACGTGAAGCCCATCGAGGAC & GGAGCACCTTGGCGAACAGC \\
FABP4 & TCGGTGGACAAGAACAGCAACG & TCGGTGGACAAGAACAGCAACG \\
Leptin & TCACCGCAGACGACAGGAAGG & AGGCTGTCAGTCCACCAAGGG \\
Adiponectin & CAGGATCAATGACATTTCACACA & GCTGGTGAGGACCTGTTGAT \\
$\beta$-actin & GTCTCCGTGCTTCCGATGAA & GGTCAAACTGGACTTGGGGT \\
\hline
\end{tabular}

Table S2 List of antibodies

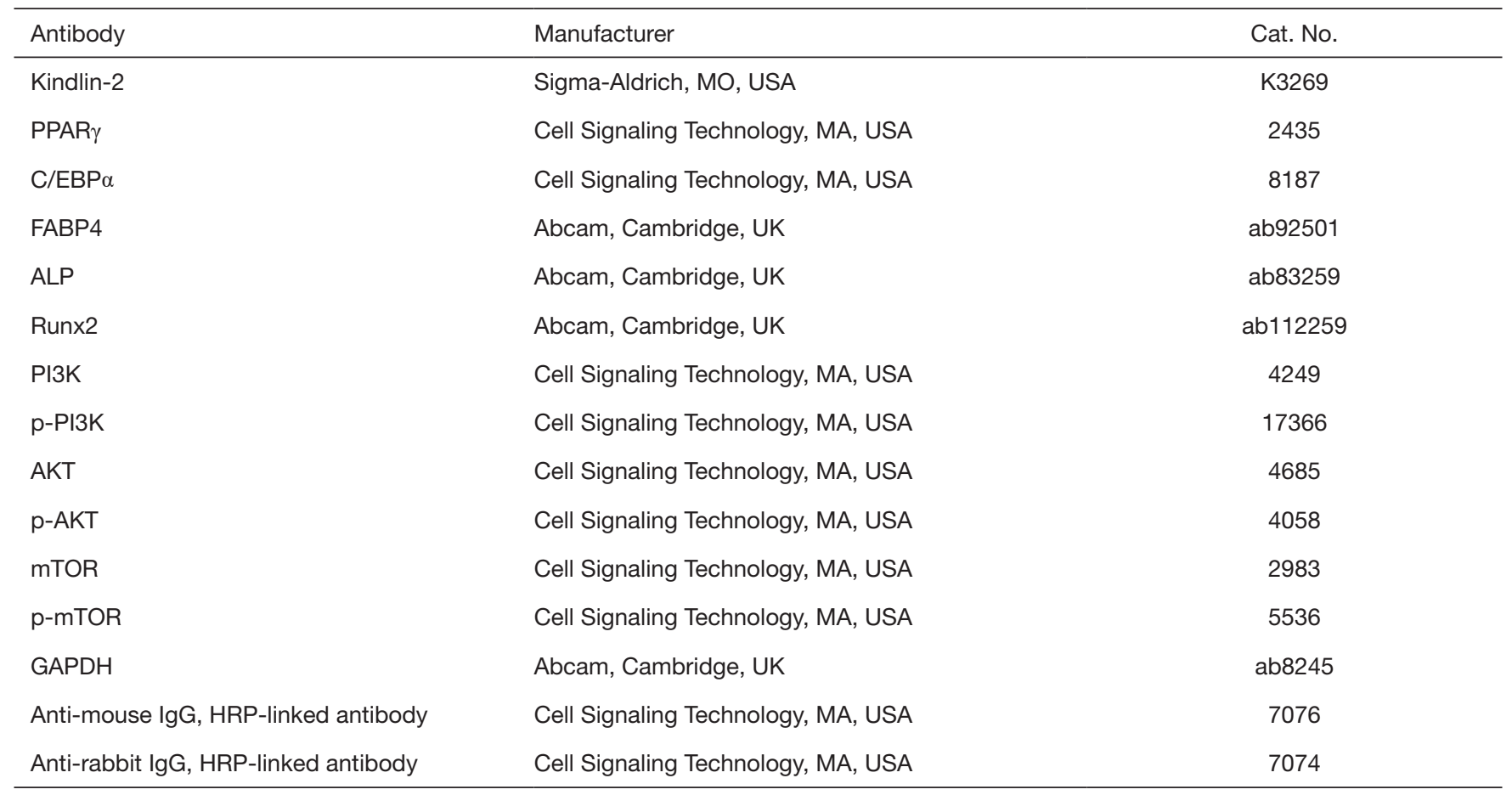

